\title{
Biomarkers of disease progression
}

\author{
Axel Petzold \\ December 22, 2016
}

\section{Introduction}

Clearly diagnostic criteria in multiple sclerosis (MS) continue evolving [1]. Once a diagnosis is made a majority of patients will want to know about their long term prognosis [2]. The difficulty in providing an accurate long term prognosis relates to the unpredictability of the disease course[3]. Biomarkers for disease progression add valuable information in this context $[4,5]$.

More precisely when seen in clinic patients ask questions such as: "How bad is my disease?" or "What is my chance for another relapse?" [6]. There will be no $100 \%$ accurate answer to these questions [2]. What can be said about disease progression will be based on an estimate of probabilities [7]. Biomarkers can be used to statistically model the probability of disease progression [8].

Disease progression due to axonal loss will be inoxerable [9]. In contrast to axonal loss, patients have a chance for recovery of function caused 
by demyelination and conduction block [10]. For this reason biomarkers which allow to assess axonal loss in MS are of particular interest for this chapter no disease progression $[11,12]$.

\section{Biomarker definitions}

The National Institutes of Health $(\mathrm{NIH})$ workshop on biomarkers definitions are:

- Biomarker: "a characteristic that is objectively measured and evaluated as an indicator of normal biologic processes, pathogenic processes, or pharmacological responses to therapeutic intervention." [13] Biomarkers may be sub-classified into:

- Process biomarkers: biomarkers which allow monitoring of the dynamics and activity of pathological features.

- Predictive biomarkers: biomarkers which can narrow the choices between treatment options [14].

- Prognostic biomarkers: biomarkers which are associated with a clinical outcome, such as a time-to-event outcome [14].

- Surrogate endpoint: "defines a biomarker that is intended to serve as a substitute of a clinically meaningful endpoint and is expected to predict the effect of a therapeutic intervention or the evolution of disease. [13]" 
- Clinical endpoint: "defines a meaningful measure which captures how a patient feels, functions or survives. [13]" Clinical endpoints can be broken down to:

- Time-to-event outcome: The time until a predefined event occurs, e.g. the time to reaching a certain score on the Expanded Disability Status Scale score (EDSS) [15] ranging from 0 (normal) to 10 (death due to multiple sclerosis).

- Intermediate endpoint: represents "a clinical endpoint that is not the ultimate outcome but is nonetheless of real clinical usefulness. [13] “ (e.g. a clinical scale $[15,16]$.

- Ultimate clinical outcome: represents "a clinical endpoint reflective of accumulation of irreversible morbidity and survival. [13]"

\section{Biomarkers for axonal loss}

Simplified, there are two types of biomarkers: (1) those which are detectable during the acute phase of axonal loss [17] and (2) those which can document the loss of axons at a later stage [18]:

1. Early biomarkers of axonal loss:

- Body fluid biomarkers released during axonal disintegration [11, 19]

- In vivo apoptosis markers [20]

2. Late biomarkers of axonal loss: 
- Magnetic resonnance imaging (MRI) of the brain [21]

- Optical coherence tomography (OCT) of the retina $[22,23]$

- Multimodal evoked potentials[24]

This chapter does focuse on early biomarkers of axonal loss, which are body fluid biomarkers [25]. Historically, much of body fluid biomarker research in MS was conducted in the cerebrospinal fluid (CSF) [4]. This concept has substantially developed over the past years following discovery of the glympatic system [26].

\section{The cerebrospinal fluid (CSF)}

Normal CSF is clear and colorless and $70 \%$ the CSF water content originates from the choroid plexus [4]. The CSF represents and ultrafiltrate derrived from the choroid plexus which has a filtration rate of about 40 $\mathrm{mL} / \mathrm{h}$ [27]. Only about $30 \%$ of the CSF water comes from the meninges and the blood-nerve barrier wich is located at level of the nerve roots. For biomarker research in MS it is important to realise that CSF water also comes from the interstial fluid (ISF) of the brain parenchyma [28]. Synonymous to ISF the literature used the term extracellular fluid (ECF) $[28,29]$. The relationship of the four different brain fluid compartments is summarised in Figure 1. Because plasma proteins diffuse through the blood-nerve barrier along the entire length of the spinal cord they are highest in the lumbar CSF.

About $80 \%$ of the CSF proteins originate from the plasma and only $20 \%$ 


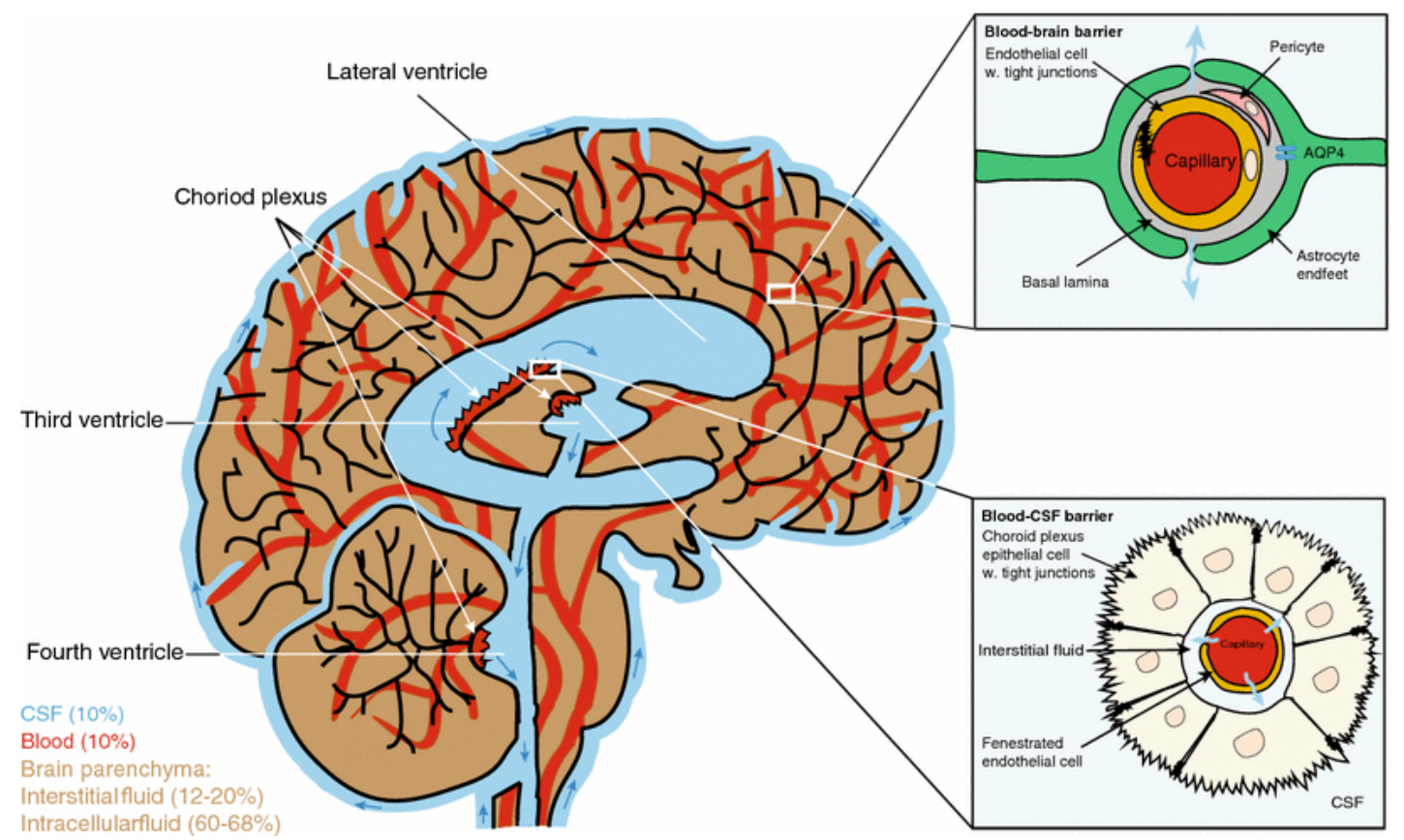

Figure 1: Schematic representation of the brainâs fluid compartments and barriers. The fluid compartments in the brain consist of intracellular fluid (ICF) (60-68\%), interstitial fluid (ISF) (also known as extracellular fluid) (12-20\%), blood (10\%) and the cerebrospinal fluid (CSF) (10\%). Blood is separated from the CSF and interstitial fluid by the blood brain barrier (BBB) and blood-CSF barrier, respectively. Tight junctions between the blood endothelial cells constitute the $B B B$, restricting macromolecules to move freely from the blood into the brain parenchyma. Fluid and solutes diffusses into the brain parenchyma from the perivascular space located between endothelial cells and astrocytic endfeet that expresses the water channel aquaporin-4 (AQP4). The blood-CSF barrier is formed by tight junctions between the choroid plexus epithelial cells. Macromolecules from the blood can move freely between the fenestrated endothelial cells to the interstitial fluid but is restricted by tight junctions in the choroid plexus epithelial cells, which therefore are believed to be the main players in determining CSF composition. [Figure reproduced with permission from [26]]. 
come from the brain parenchyma. Overall, the CSF has a much lower protein concentration ( $\approx 350 \mathrm{~g} / \mathrm{L}$ ) compared to the serum $(70,000 \mathrm{~g} / \mathrm{L})$. Nevertheless, biomarkers released by pathology of the brain parenchyma, such as formation of MS lesions or axonal loss will in most cases outweight the prportion of similar proteins transferred from the blood. This may change with a defective blood brain barrier which may allow for proteins to leak from the blood into the CSF.

\section{The Blood brain barrier}

The blood brain barrier (BBB) acts as a filter preventing the unselective diffusion of compounds into the human brain (Figure 1). To be precise the anatomically defined BBB needs to be distinguished from the functionally defined blood-CSF barrier (BCB). The BCB is a sieve permitting small substances to diffuse from the blood into the CSF [30].

At time of writin the goldstandard for assessment of the BBB/BCB function is stil based on the measurement of albumin in the CSF and serum [31]. With an intact $B B B / B C B$ only a small amount of albumin can diffuse into the CSF (normal range $\approx 144-336 \mathrm{mg} / \mathrm{L}$ ). In normal conditions, the CSF to serum albumin quotient is smaller than 0.0074. With breakdown of the BCB, serum albumin leaks into the ISF and CSF, the CSF albumin rises and the CSF to serum albumin quotient increases.

Sampling of the ISF is more challenging compared to the CSF and typically require microdialysis techniques [32]. Because it is not ethical to use this invasive technique in patients with MS progress in the field comes 
from neurointensive care units [29] and experimental studies [33]. There is a continous fluid exchange between the CSF and ISF. Whilst conventional wisdom used to be that osmotic gradients were most relevant, more recent evidence points towards relevance of connective influx of the CSF [33].

\section{The glymphatic system}

The brain glymphatic hypothesis states that hydrostatic pressure is relevant for trans-astrocytic water flow [33]. Pulsation of blood vessels drives water through AQP4 channels (Figure 2). The AQP4 channels are highly expressed at the astrocytic footprocesses which makes them a relevant autoimmune target in neuromyelitis optica [34]. The glymphatic system proposes that the CSF influx to the brain parenchyma promotes convective ICF flow, ultimately directed at the perivenous space. Because of simlarities with the lymphatic system, and the special role taken by glial cells, the terim "glymphatic' was introduced [26]. The diurnal activity of the glymphatic system is considerable with highest activity during sleep. This has thought to be relevant for removal of compounds. The brain glymphatic system is particularly relevant for the clearance of proteins and protein breakdown products involved in neurodegenerative pathology.

The role of the glymphatic system in MS has not yet been studied in detail and its role for driving autoimmunity is unclear [35]. Given the access difficulties to the brain ICF in vivo in MS it will not be straightforward to adress these questions. Because of developmental similarities between the brain and retina three different lines of research suggested presence 


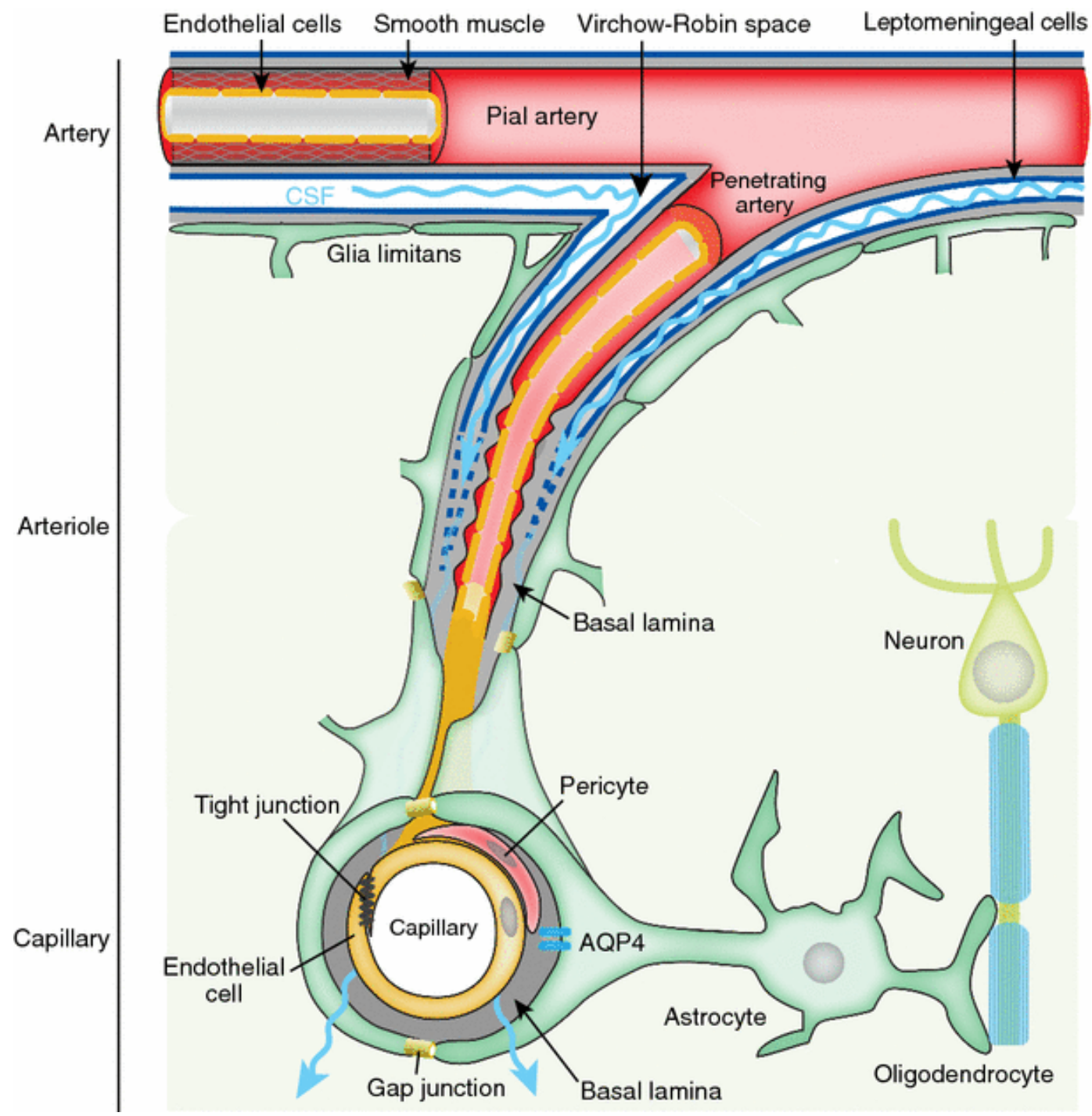

Figure 2: The neurovascular unit. The structure and function of the neurovascular unit allow bidirectional communication between the microvasculature and neurons, with astrocytes playing intermediary roles. Pial arteries in the subarachnoid space bathed in CSF become penetrating arteries upon diving into the brain parenchyma. The perivascular space around penetrating arteries is termed the VirchowâRobin space. As the penetrating arteries branch into arterioles and capillaries, the CSFcontaining Virchow-Robin spaces narrow and finally disappear. CSF from the Virchow-Robin spaces continues its flow into the perivascular spaces around arterioles, capillaries and venules where the extracellular matrix of the basal lamina provides a continuity of the fluid space. Astrocytic vascular endfeet expressing aquaporin-4 (AQP4) surround the entire vasculature and form the boundary of the perivascular spaces. [Figure reproduced with permission from [26]]. 
of a retinal glymphatic system $[36,37,38]$. The existence of a retinal glymphatic system has not yet been shown experimentally. One advantage of investigating the presumed retinal glymphatic system in MS is that this can readily be done using non-invasive imaging techniques such as OCT $[22,23]$.

\section{Early biomarkers for axonal loss}

In MS disintegration of the axonal membrane causes release of the cytoplasmatic content from injured axons the surrounding extracellular fluid (ECF, ISF) of the human brain [29]. The glymphatic system faclitates flux of these substances from the brain ECF/ISF into the blood stream from where they can be sampled and quantified. Sampling from the blood as opposed from the CSF has hughe advantages for longitudinal studies in MS [39].

Of note, some biomarkers are only expressed by certain cell types. They are called cell-type-specific biomarkers. The measurement of celltype specific biomarkers indirectly permits to estimate the degree of e.g. axonal loss. Table 1 summarises cell-type-specific and other biomarkers.

Table 1: Potential and established biomarkers and their cellular sources.

Biomarkers for the neuron and axon are of particular interest for disease progression in MS. (Table updated from reference [40])

\begin{tabular}{lccccc}
\hline CSF & Neuron & Astro- & Micro- & Oligoden- & Choroid \\
Biomarker & \& Axon & cyte & glia & drocyte & plexus \\
\hline $14-3-3 \gamma$ & ++ & + & + & + &
\end{tabular}


ABP

AD7c-NTP

Albumin

$\alpha$ spectrin

$\alpha(1) \mathrm{BG}$

$\alpha$-internexin

ApoE

$\beta$-tubulin

$\beta$-2-Microglobulin

$\beta$-trace

Bri2-23

CHI3L1

Chromagrannins A \& B

Clusterin

Cystatin C

EDG-8

FABPs

FFA

Ferritin

GFAP

Glucose

Glutamate

HK6

HNE

Hypocretin-1

Isoprostanes

Lactate

MAG

MBP

MDA 


\begin{tabular}{|c|c|c|c|c|c|}
\hline MOBP & & & & + & \\
\hline MOG & & & & + & \\
\hline NAA & ++ & + & + & + & \\
\hline NCAM & + & & & + & \\
\hline NOx & + & + & + & & \\
\hline NSE & + & & & & \\
\hline Neurotrophins & + & + & + & + & \\
\hline $\mathrm{Nf}(\mathrm{NfL}, \mathrm{NfM}, \mathrm{NfH})$ & ++ & & & & \\
\hline OMgp & & & & + & \\
\hline Osteopontin & + & + & + & + & \\
\hline PLP & & & & + & \\
\hline PrPc & + & & & & \\
\hline Pyruvate & + & + & + & + & \\
\hline S100B & & ++ & & + & \\
\hline SFas (sCD95) & + & & & & \\
\hline Tau & + & + & + & + & \\
\hline Transthyretin & & & & & + \\
\hline Ubiquitin & + & + & + & + & \\
\hline UCHL-1 & ++ & & & & \\
\hline Vimentin & + & + & + & & \\
\hline YKL-40 (human chitinase 3-like 1 protein) & & & + & & \\
\hline
\end{tabular}

Challenges for biomarkers in MS The challenges for biomarkers in MS are the pathological disease heterogeneity, the highly variable clinical course and the subclinical disease course with acute relapse related damge on top of pre-existig damage. Probably this problem is greatest for any biomarker which is not specific for the neuro-axonal compartment. For example the glial biomarkers S100B or glial fibrillary acidic protein 
(GFAP) will be increased following acute relpase related glial activation as well as after formation of a glial scar later in the disease course [41]. Even more difficult are biomarkers indicating systemic inflammation independent to whether or not there are acute MS lesions forming in the brain [42]. In contrast, a rise of biomarkers specific for the axonal compartment are likely to indicate acute damage to the one structure hold responsible for disability progression [43]. To add value, a biomarker should improve on the clinical prognostic accuracy.

At disease onset either the optic nerve, spinal cord or brainstem are affected in $85 \%$ of cases [44]. The risk for developing MS is higher with spinal cord involvement compared to isolated optic nerve pathology. About $85 \%$ of patients develop a relapsing remitting disease course [45]. Once patients reach an EDSS of 4 they disease course seems to progress inoxerably. A large proportion of these patients will lose their ability to walk independently (EDSS 6) within 20.1 years of diease onset and will be wheelchair-bound (EDSS 7) within 29.9 years of disease onset [46]. The prognosis is much better in patients presenting with MS optic neuritis (MSON) [47]. Of note not all patients presenting with optic neuritis (ON) or transverse myelitis (TM) develop MS [6]. This implies that a biomarker result cannot be interpreted in isolation, but needs to be seen as an extension of the clinical assessment. 


\section{CSF biomarkers in MS}

There is no diagnostic biomarker for MS. Data from the available biomarkers are best interpreted in knowledge of a comprehensive CSF analysis.

\section{Routine CSF analysis}

The reason for a standardised basic CSF analysis is that the specificity for any biomarker in the differential diagnosis of MS improves [4]. There are six core points to be considered:

1. Any biomarker should only be regarded as an extension of the clinical assessment

2. CSF cytology:

- A high red blood cell count $\left(5 \times 10^{9} / \mathrm{L}\right.$ to $\left.7 \times 10^{9} / \mathrm{L}\right)$ in the absence of bilirubin (assessed by spectophotometry) suggests a traumatic tap. This may render other quantitative tests uninterpretable

- A slightly raised white cell count $\left(>5 \times 10^{6} / \mathrm{L}\right)$ may be found in up to $34 \%$ of patients with MS

- A high white cell count $\left(>50 \times 10^{6} / \mathrm{L}\right)$ is unusual in MS

3. CSF glucose: the CSF/serum ratio should be $>0.4$; low CSF glucose levels suggest an infectious process 
4. CSF total protein: a very high CSF total protein content $(>1 \mathrm{~g} / \mathrm{L})$ suggests an infectious or neoplastic process. High CSF total protein is occasionally seen in patients with CIDP who also have central demyelination

5. CSF/serum albumin quotient: allows assessment of the integrity of the blood-CSF barrier and is the basis for quantitative models on intrathecal immunoglobulins

6. CSF lactate: an increase in CSF lactate $(>2.4 \mathrm{nmol} / \mathrm{L})$ is unusual in MS and may suggest mitochondrial or infectious pathology

Good clinical selection and a basic CSF program help to minimise pre-analytical pitfalls leading to a false-positive or false-negative CSF biomarker results.

\section{Intrathecal IgG synthesis - CSF oligoclonal bands}

Currently diagnosis of multiple sclerosis is based on dissemination in time and space. Before 2010 lack of MRI evidence for dissemination in space could be substituted by a paraclinical test, CSF oligoclonal bands (OCB). A debate followed discussing the value of cerebrospinal fluid (CSF) analysis $[48,49,50]$. These arguments have been refined over the subsequent 5 years $[51,52,51]$. The authors have one point in common which is illustrated by a personal case. 


\section{Illustrative clinical case}

In February 2011, a 41-year old, right-handed man experienced an episode of vertigo. His general practitioner noticed a nystagmus and referred him to the Ear, Nose and Throat (ENT) specialist. The vertigo was thought to be central in origin and a MRI was requested. This MRI demonstrated multiple paraventricular T2-lesions (Figure 3 A). By May 2011 the patient had made a full recovery.

In July 2011 he developed pain on eye-movements in his right eye. About one week later his vision started to deteriorate. He was referred to a Neurologist, who diagnosed optic neuritis. Visual evoked potentials (VEP) of the right eye were severely prolonged (P100, $125 \mathrm{~ms})$. A repeat MRI did not show any new lesions (Figure 3 A). A subsequent lumbar puncture revealed intrathecally-synthesised oligoclonal bands (type 2 pattern, see below).

Taken together there were two attacks, one of which was clinically confirmed by a neurologist. Radiologically this patient did not fulfil DIS or DIT [53]. A diagnosis of MS could not be made in 2011 [53]. A year earlier, however the patient would been diagnosed with MS because evidence of intrathecally-produced lgG would have been a substitute for radiological DIS $[54,55]$.

\section{CSF OCB - anlaytical aspects}

One frequently cited criticism of CSF OCB has to do with reproducibility. Why does one laboratory get a different result compared to another labo- 


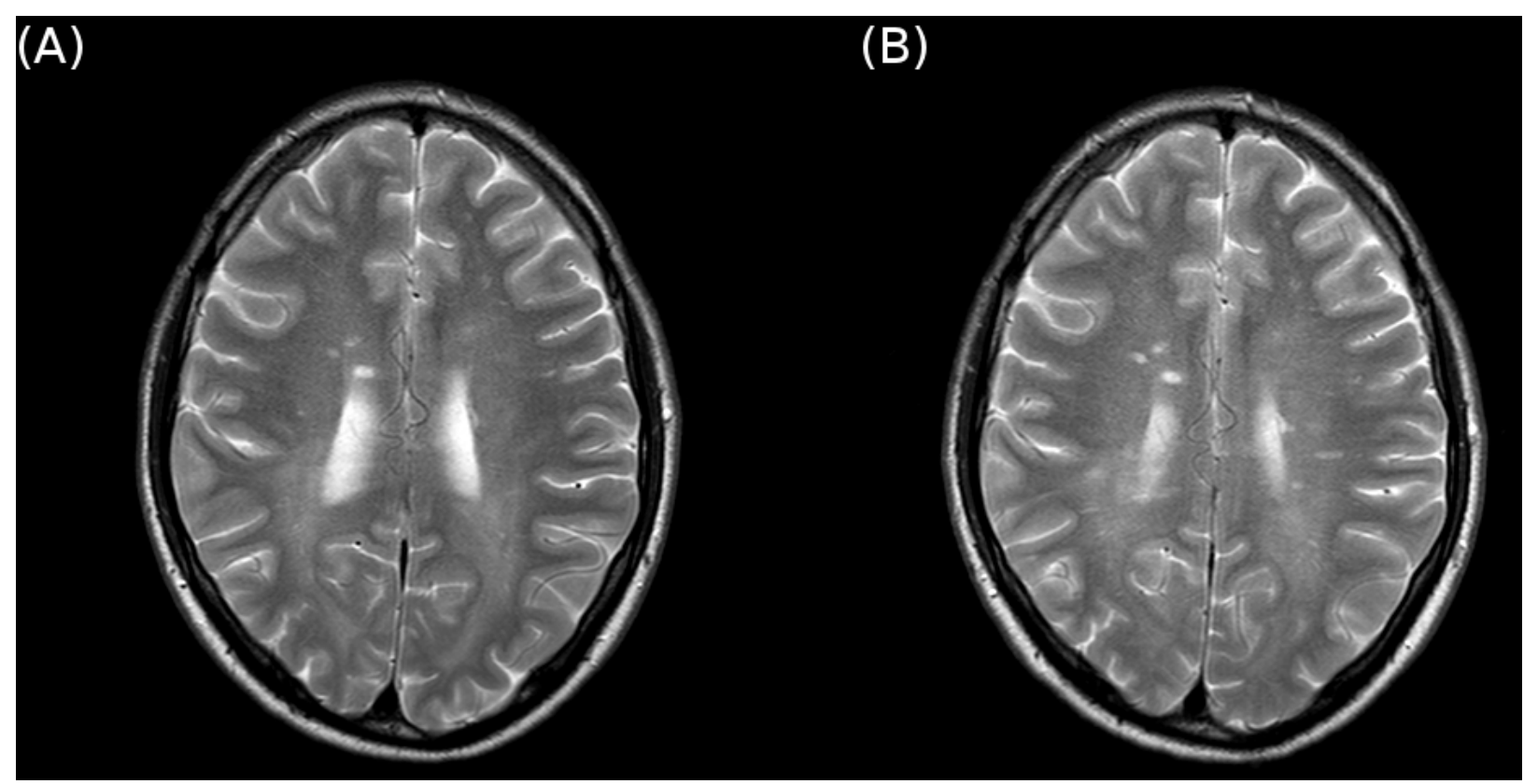

Figure 3: MRI brain of a 41 year-old man demonstrating non-contrast enhancing T-2 lesions exclusively located in the paraventricular regions in (A) April 2011 and (B) July 2011. 


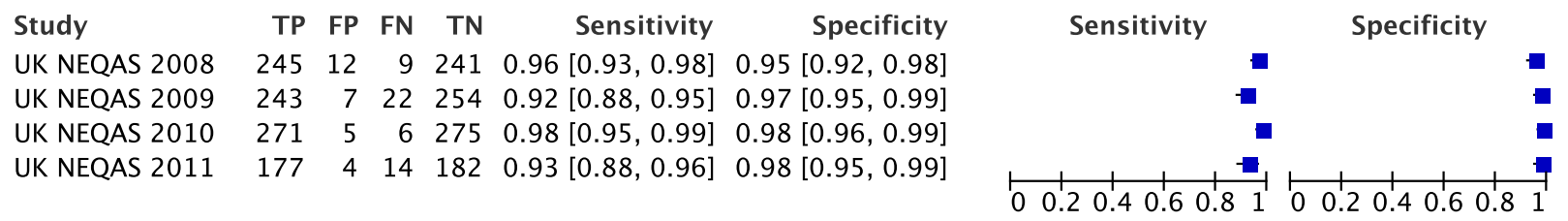

Figure 4: Forest plot of the analytical accuracy of reporting CSF OCB from 114 laboratories participating in an external quality control scheme (data kindly provided by UK NEQAS, 12.10.2011). [Reprinted with permission from [60]]

ratory? And which laboratory should one believe?

There is evidence that poor analytical quality can cause a loss of sensitivity (45\%-77\%) much efforts had been made to optimise sample collection and processing [56]. Teunissen et al have written an influential standardisation protocol for CSF analysis in MS [57]. In addition, specific recommendations for CSF OCB analysis have been developed [58].

Adhering to these guidelines an almost perfect inter-laboratory agreement (kappa >0.8) was found for 19 Spanish laboratories [59]. Likewise, data were excellent for 114 UK laboratories which participated in an external national quality assessment service (UK NEQAS)between 2008 to 2011. The analytical sensitivity ranged from $92-98 \%$ and the analytical specificity from 95-98\% (Figure 4). Taken together these data suggest that lessons have been learned and a level of analytical accuracy been reached with is acceptable. 


\section{The source of CSF OCB}

The immunesystem requires B-cells to produce IgG. Each of us has about $10^{9}$ distinct $\mathrm{B}-$-cell clones. The B-cells reside in the meninges and parenchyma of the CNS $[61,62]$. Only a small number of B-cell clones are present in the CNS [63]. Therefore any intrathecally-produced IgG can only ever be oligoclonal. This oligoclonal IgG is seen as a "band" on IEF, the preferred method [58]. Hence the name OCB.

Clonally-expanded B-cells from the CSF were shown to be the source of matching CSF IgG $[64,65]$.

The enormous diversity of $\lg G$ antibodies is achieved by $\lg G$ gene rearrangement (somatic hypermutation) during B-cell development (clonal expansion) [66]. This is done in a precise order. Firstly the heavy chain rearranges. Once a functional heavy chain results, the kappa chain rearranges. If kappa is unproductive (or cannot pair with the heavy chain) then lambda will rearrange.

The impressive antibody diversity is needed because of the potential threat any intruding molecule/organism poses to the human body. The immune system cannot risk leaving all the defense to one single clone of B-cells: the IgG may not be effective, e.g. because the target antigen may change, be masked or be shed. For these reasons any systemic infection triggers an oligoclonal response. Consequently a large number of B-cells are recruited and stimulated by cytokines. What is seen as polyclonal IgG in the serum is probably the result of this massive cytokine stimulation resulting in activity of B-cells. Each of these B-cell clones produces a 
slightly differently composed IgG molecule targeted at the potential antigen threat. Over time, particularly effective clones may be selected. This process is not fully understood and modification of B-cells in the germinal centers plays a role alongside somatic mutations and affinity maturation.

In the CNS only a small number of B-cell clones are present in the CNS. Hence the intrathecal B-cell immune response can only ever be oligoclonal. Further development of analytical techniques may reveal more about the different clones and their immunoglobulins.

From a biological point of view there appears to be a continuum from the systemic polycoclonal immune response to the oligoclonal, and occasionally monoclonal, immune response observed in the CNS. Any process triggering a B-cell response may lead to the presence of $\operatorname{lgG}$ in the CSF.

\section{Five keys to understanding CSF OCB}

Five simple keys to interprete OCBs restuls are:

- In normal CSF all IgG comes from the blood by passive diffusion

- In normal CSF and serum IgG is polyclonal

- Oligoclonal bands in blood give a mirror pattern in CSF

- Local synthesis is present when there are bands in the CSF that are absent from the serum

- Oligoclonal bands are (generally) a sign of pathology 
Table 2: Diseases in which intrathecal oligoclonal IgG has been reported. $R R M S$ = remitting relapsing MS, SPMS = secondary progressive MS, CIS = clinically isolated syndrome, $C N S=$ central nervous system, NMO = neuromyelitis optica, $A D E M=$ acute demyelinating encephalomyelitis, LETM = longitudinal extensive transverse myelitis, $S L E=$ systemic lupus erythematosus, $B I H$ = benign intracranial hypertension, GBS = Guillain-Barré Syndrome. [Reprinted with permission from [60]].

\begin{tabular}{llll}
\hline MS type & Autoimmune & Inflammation & Other \\
\hline RRMS & SLE & Neurosyphilis & Paraneoplastic disorders \\
SPMS & Behcet's disease & Neuroborreliosis & Aseptic meningitis \\
PPMS & Neurosarcoidosis & HIV infection & Cerebral tumors \\
CIS & Sjögren's syndrome & Herpes viridae & Cerebral lymphoma \\
NMO & Morvan syndrome & Chlamydia & Vertigo \\
ADEM & Anti-NMDA encephalitis & Neurotuberculosis & Alzheimer \\
LETM & Anticardiolipin syndrome & HTLV myelopathy & Prion disease \\
& Autoimmune encephalopathy & Schistosomiasis & Migraine \\
& Stiff-man syndrome & Cerebral cysticercosis & Syncope \\
& GBS & CNS vasculitis & BIH \\
\hline
\end{tabular}

\section{CSF OCB are not specific for MS}

Presence of CSF OCB has been described in MS and a range of other diseases (Table 2) $[67,68,69,70,71,72,73,74,75,76,77,78,79,80$, 81, 82, 83, 84, 85, 86]. The interpretation CSF OCB will depend on the clinical situation. Presence of CSF OCB can be taken as an indicator for a pathological relevant autoimmune process, an epiphenomenon or an inflammatory response. This interpretation will depend on the pattern of OCB seen on IEF. 


\section{Five OCB patterns}

The current recommendations are to use IEF for detection of OCB [58]. This is a qualitative technique. Therefore pattern recognition is crucial. It was suggested that the observed patterns be designated as "Type 1" to "Type 5" [58].

Figure 5 shows the 5 classical patterns and one more which can be relevant:

- Type 1: no bands in CSF and serum (S)

- Type 2: oligoclonal lgG bands in CSF, not in the serum, indicative of intrathecal IgG synthesis.

- Type 3: oligoclonal bands in the CSF (like Type 2) and additional identical oligoclonal bands in CSF and serum samples.

- Type 4: identical oligoclonal bands in CSF and serum indicating a systemic rather than an intrathecal immune reaction, with a leaky or normal or abnormal blood-CSF barrier and oligoclonal bands passively transferred into the CSF.

- Type 5: monoclonal bands in the CSF and serum sample seen in the presence of a paraprotein (monoclonal lgG component).

For didactic reasons mnemonics may come useful to remember the CSF OCB patterns.

- Normal: no bands in CSF and serum (type 1 [58]) 


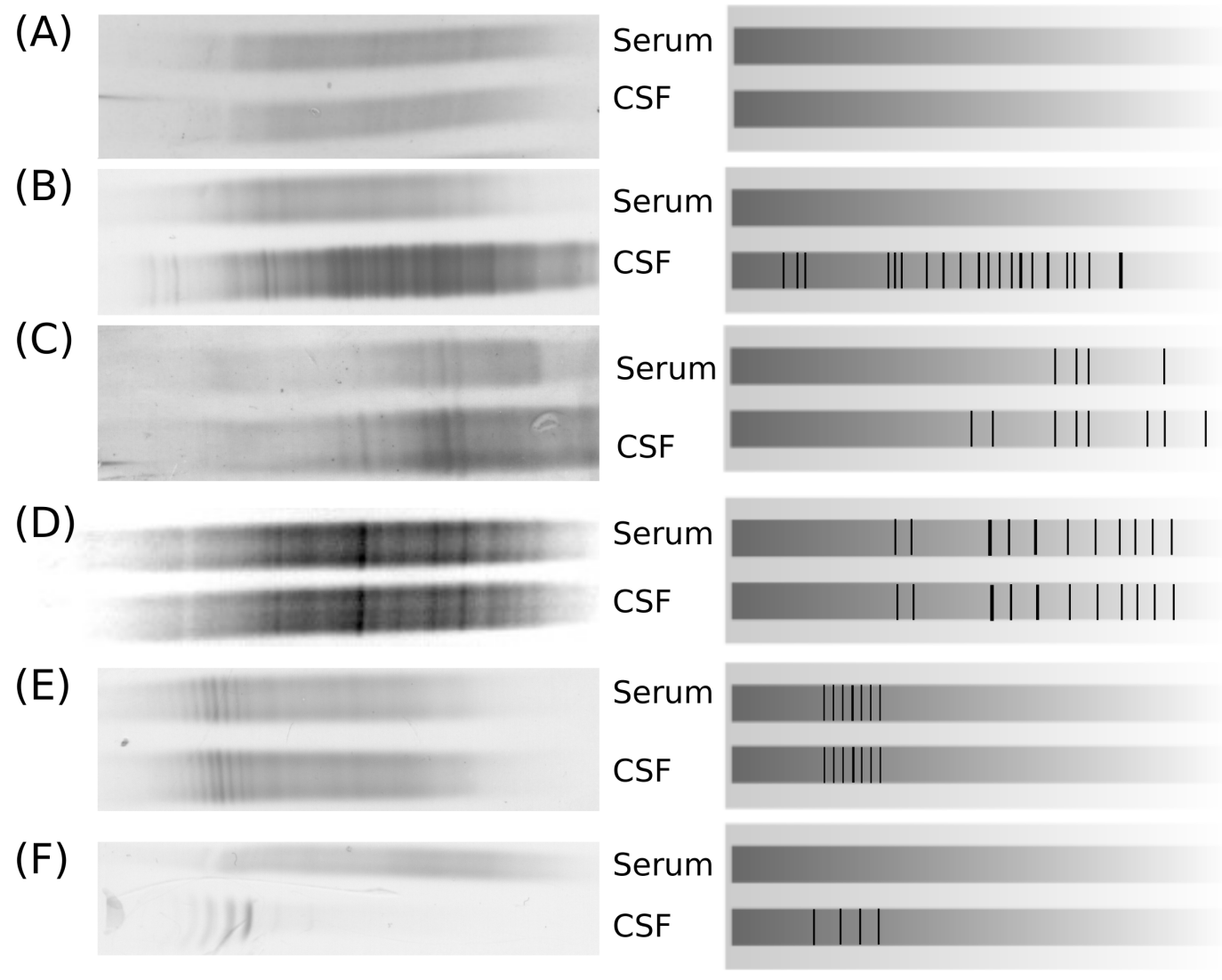

Figure 5: The OCB patterns shown are (A) normal (no evidence for intrathecally-produced oligoclonal IgG, Type 1), (B) local synthesis (Type 2), (C) a mirror plus pattern (more bands in the CSF compared to the serum, Type 4), (D) a mirror pattern (equal number of matched bands in CSF and serum, Type 3), (E) mirror steps (monoclonal bands, Type 5), (F) an artifact $t^{\dagger}$ Shown is the original photograph to the left and an illustrative, high contrast sketch to the right of the image. [Reprinted with permission from [60]]. 
- Local: oligoclonal bands in CSF but not in the serum, indicative of isolated intrathecal oligoclonal lgG synthesis (type 2 [58])

- Mirror: identical oligoclonal bands in CSF and serum, indicating a systemic rather than an intrathecal immune reaction where oligoclonal bands are passively transferred into the CSF (type 4 [58])

- Mirror plus: oligoclonal bands in the CSF and additional identical oligoclonal bands in CSF and serum samples, the space between bands is irregular (type 3 [58])

- Mirror steps: monoclonal bands in the CSF and serum sample seen in the presence of a paraprotein (monoclonal lgG component), spaced in symmetric steps (type 5 [58])

- Artifact: bands caused by pre-analytical or analytical problems

\section{Interpretation of OCB patterns}

Type 1 is easy: this is a negative test result. However, absence of evidence does not necessary provide evidence for absence. Figure 6 shows the IEF pattern of a patient with a clinical isolated syndrome (CIS) in 2004 and again 18 months later. Clearly a Type 2 pattern has developed and the patient then fullfilled the criteria for definite MS. If the clinical picture strongly suggests a diagnosis of MS, then a repeat lumbar puncture may be indicated in any patient with initially OCB-negative CSF.

Type 2 is also straight forward: specific bands are present in the CSF but not in the serum. This pattern is observed in patients with MS. It can 


\section{CIS 2004 CSF

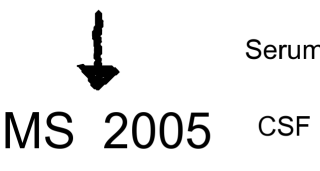 \\ Serum}

Figure 6: The CSF in a patient presenting with CIS who showed no evidence of intrathecal IgG in 2004 but developed oligoclonal lgG bands in 2005.

be as discrete as shown in Figure 6 or as strong as shown in Figure 5. MS is probably the disease with the strongest stimulation of the B-cell clones within the CNS parenchyma. But, as mentioned above, OCBs are also seen in a number of other diseases, with the present list likely to be incomplete. An oligoclonal pattern in the CSF is pathological and requires further investigation.

The interpretation of Type 3 and 4 patterns is more complex [58]. In particular, Type 4 can be misinterpreted if the amount of $\lg G$ in the serum is too high, as this can blur the serum bands. This is one reason for adding equal amounts of IgG from the CSF and the serum sample [58, 87]. Type 4 can be seen in conditions such as Guillain-Barré syndrome. Type 5 indicates the presence of a monoclonal gammopathy, but IEF resolves what would be a single band using other electrophoretic techniques, into multiple bands differing by $1 \mathrm{U}$ of charge. This peculiarity is probably due to post-translational modifications such as glycosylation. 


\section{CSF monoclonal band}

McCombe et al. found a CSF monoclonal band in 3/1490 of CSF samples [88]. The diagnoses were lymphoma or lymphomatoid granulomatosis within or adjacent to the nervous system in two patients and a chronic inflammatory demyelinating polyneuropathy in the third. Ben-Hur et al. (using the less sensitive agarose electrophoresis) described 20 patients with a CSF monoclonal band [89]. The diagnoses were clinically definite MS, probable MS, CIS, SLE, paraneoplastic syndrome, peripheral neuropathies, superficial siderosis and torsion dystonia.

Davies et al. performed a repeat lumbar puncture in 31 patients who had a monoclonal band in the CSF but not in the serum [90]. All patients who developed clinically definite MS also converted from an intrathecal monoclonal to a oligoclonal pattern. The results of this study are shown in Table 3.

\section{Number CSF OCB bands}

It has been proposed that a higher number of bands may be of prognostic or diagnostic value. Bourahoui et al. concluded that the presence of $\geq 10$ bands in the CSF was highly specific for MS [69].

In contrast, Koch et al. on 143 patients (110 OCB positive, 33 OCB negative) did not find any relationship between the presence and number (or absence) of CSF OCB bands and either disease progression or MS subgroups (RR, SP, PP disease) [91]. The percentage of OCB-negative 
Table 3: The fate and differential diagnosis of CSF monoclonal bands. (Table adapted with permission from reference [90].

\begin{tabular}{|c|c|c|}
\hline $\begin{array}{l}\text { CSF } \\
\text { findings }\end{array}$ & $\begin{array}{l}\text { No. of } \\
\text { patients }\end{array}$ & Diagnosis \\
\hline $\begin{array}{l}\text { Conversion from in- } \\
\text { trathecal monoclonal } \\
\text { band to an intrathecal } \\
\text { oligoclonal pattern }\end{array}$ & 9 & $\begin{array}{l}3 \mathrm{MS}, 2 \text { CIS, } 1 \text { CNS inflamma- } \\
\text { tion, } 2 \text { vascular disease, } 1 \text { No di- } \\
\text { agnosis was reached }\end{array}$ \\
\hline $\begin{array}{l}\text { Persisting intrathecal } \\
\text { monoclonal band }\end{array}$ & 13 & $\begin{array}{l}1 \text { CIS, } 2 \text { Encephalitis, } 1 \\
\text { CNS inflammation, } 1 \text { cere- } \\
\text { bral lymphoma, } 1 \text { axonal } \\
\text { neuropathy, } 7 \text { More with- } \\
\text { out evidence for CNS infec- } \\
\text { tion/inflammation/demyelination }\end{array}$ \\
\hline $\begin{array}{l}\text { Initial single intrathe- } \\
\text { cal clone with normal } \\
\text { CSF IEF on follow-up }\end{array}$ & 5 & $\begin{array}{l}1 \mathrm{CIS}, 2 \text { encephalitis, } 1 \text { CNS in- } \\
\text { flammation, } 1 \text { axonal neuropa- } \\
\text { thy }\end{array}$ \\
\hline
\end{tabular}

MS patients (23\%) in this study was higher compared to the studies shown in Table ??, with all groups using IEF followed by IgG specific immunofixation.

There are two potential problems:

- absent OCBs in MS are rare. Are there any pre-analytical (diagnostic) or analytical (sensitivity) reasons for this?

- counting the number of bands in the CSF may not be a true reflection of the number of B-cell clones producing the bands. Posttranslational modification of IgG (see Figure 7) probably also includes changes in the disulfide bonds which changes the pl, resulting in a differential migration in the electric field. Therefore different lgG bands seen on the immunoblot may originate from the same clone. In order to address the biological relevance of OCBs, the number of 


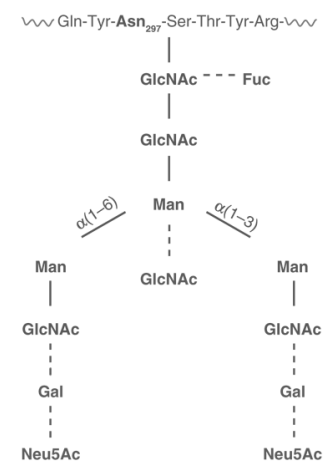

Figure 7: Representative diantennary-type oligosaccharide structure found in association with the FC moiety of human polyclonal IgG molecules. Straight lines indicate the core and dotted lines the outer arm sugar residues. Differential glycosylation at these residues can change the net charge of the $\lg G$ molecule and thus its IEF migration (Figure reproduced with permission from reference [92].

clones producing the bands (reflecting the vigor of the immune response) may turn out to be more relevant than merely the number of bands present.

\section{CSF light chains}

As mentioned above, one B-cell clone can only express either kappa or lambda light chains. Because kappa is rearranged first, it is quantitatively the dominant light chain in the human body. Therefore the kappa light chain (free and bound) is found more frequently in the CSF than lambda.

In practise, immunoblotting for kappa/lambda light chains can be helpful in the following situations:

- when a ladder (Figure 8) is seen with total IgG. This could be due to 
post-translational modifications of one single lgG molecule. Kappa/lambda staining decides whether this $\lg G$ is monoclonal. Monoclonal $\lg G$ only stains for one light chain.

- where it is uncertain whether or not very faint bands are present. In one study [93] we found that the sensitivity for detecting OCBs in the CSF in clinically-definite MS patients increased from $89 \%$ to $98 \%$ using kappa/lamba staining (unpublished data). In view of this, it may be interesting to reanalyse the CSF of those MS patients reported to be OCB-negative, using kappa/lambda staining [94, 95, 91].

- finally if there there is "negative staining" (looking very white) at the beginning of the blot (towards the cathode). This may be due to IgM which is not picked up by the IgG staining and kappa/lambda can be of help.

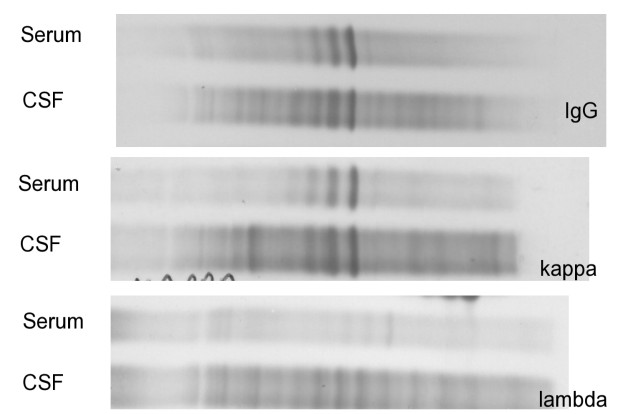

Figure 8: A "ladder" is observed for total lgG. In this situation it is useful to stain for kappa and lambda light chains. (A) total lgG, (B) free \& bound kappa and (C) free \& bound lambda. 


\section{CSF IgM OCB}

Luisa Maria Villar has pioneered the investigation of CSF IgM bands in MS for the past decade [96]. The method has been validated [97]. As in any immune-response, IgM levels increase in the serum and CSF before IgG develops. Sensitive and specific detection of CSF oligoclonal IgM bands is possible using IEF [96]. As with IgG, IgM is not specific for MS but is also found in other inflammatory CNS diseases [98]. CSF IgM was found to be of prognostic relevance in MS [99]. Importantly, CSF IgM OCB were found to be associated with axonal damage in MS [100]. In PPMS, IgM OCB were suggested to permit targetable inflammation [101]. Using OCT as an outcome measure it was possible to demonstrate an association between retinal nerve fibre atrophy and ganglion cell inner plexiform layer loss with presence of intrathecal lipid-specific CSF IgM OCBs [102].

\section{CSF OCB and the cause of MS}

On intriguing hypothesis is that identification of the $\lg G$ antigens could reveal the cause of MS [103].

To illustrate this line of though an analogy will be used. For this analogy the example refers to high-affinity CSF IgG. In this example the CSF IgG OCBs will be mostly directed against viral antigens. A convenient laboratory technique for detecting such high-affinity viral antigen specific IgG is immunoblotting. This thechnieuq is readily available in a laboratory already using IEF for OCB detection [104]. An illustrative example of such a 
high-affinity lgG immunoblot is shown in Figure 9.

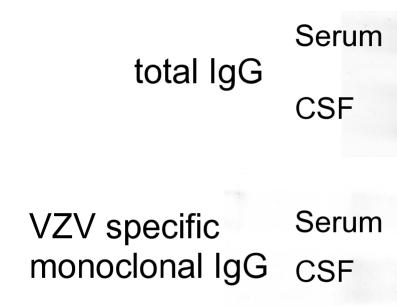

Figure 9: The antigen specific immunoblot pulls out monoclonal $\lg G$ (the Ig $G$ is distributed in a ladder pattern) directed against VZV from the polyclonal background.

Typically patients with subacute sclerosing panencephalitis (SSPE) have CSF IgG directed against the measles virus. An immunoblot against measlesspecific antigens can help to identify them (see Figure 10).

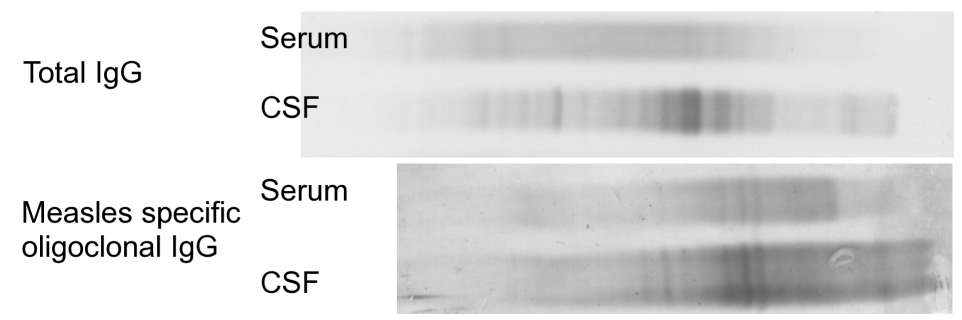

Figure 10: Local synthesis of measles-specific oligoclonal IgG in Subacute Sclerosing Progressive Encephalomyelitis (SSPE).

The interpretation of antigen-specific bands needs to consider the following:

- If the total $\lg G$ and antigen-specific $\lg G$ patterns share $>50 \%$ of bands, this probably indicates a causal relationship

- If there are multiple bands present against several viruses, this is probably an anamnestic response 
- Monoclonal antibodies may develop into oligoclonal antibodies

- The process is dynamic

To conclude with the analogy, CSF IgG is typically of high-affinity. However part of the problem in MS is that most of the CSF IgG in MS is of low affinity $[105,106,107]$. Unfortunately, attempts to identify the cause of MS using CSF OCB have not been successful. There is mounting evidence that much of the CSF OCB may represent an epiphenomenon of tissue damage.

\section{CSF OCB in MS target debris}

There is sobering evidence that CSF OCBs are directed at self-proteins [108]. The CSF OCB may therefore contribute to waste clearance by targeting debris [109].

This interpretation permits to explain some of the points made above. Firstly, absence of CSF OCB at disease onset with limited tissue damage of short duration (see Figure 6). With accumulation of tissue damage CSF OCB will develop. Second, evolution of CSF monocolonal bands to CSF OCB in patients with MS over time. Third, prognostic relevance of higher number of bands in patients with progressive tissue damage over a long period of time. Fourth, similatrities of findings for $\lg G$, $\lg M$ and light chains. Fifth, low diagnostic specificity of CSF OCB for MS if the differential diagnosis includes other inflammatory or autoimmune conditions with tissue damage (Table 2). Sixth, the low affinity of CSF OCB and the failure to discover a causative antigen. 


\section{Cell-type specific protein biomarkers in MS}

The importance for biomarkers in neuro-axonal degeneration cannot be overestimated. For a patient, loss of function due to axonal loss is likely to be permanent [110]. Simplified, loss of function can be caused by demyelination and conduction block, both of which are reversible, and axonal loss which is irreversible (Figure 11). Disintegration of the axonal membrane leads to release of axonal proteins into the ECF and CSF as described above.

Biomarkers relevant for axonal degeneration in MS research have recently been reviewed $[112,113,114]$. Axonal biomarkers can distinguish between MS subtypes $[115,116,117,118]$. Of these, neurofilaments were most consistently found to be of prognostic relevance $[117,118,119,120$, $121,122,123,115,124,125,126,127,128,129$ ] (Table ??). There is evidence for axonal transport deficits in MS affecting $\mathrm{Nf}$ as a cargo to the motor protein KIF5A [130].

At present neurofilaments are probably one of the most promising axonal biomarkers in conditions with substantial axonal loss [131, 132, 133, $116,121,134,135,128,127,136,137,138,139,140,141]$. The concept has been validated in animal and cell-culture experiments [142, 19]. A number of analytical techniques have been developed to this purpose $[131,143,144,145,146,147,148,39]$.

Simplified, this is demonstrated in Figure 12. Firstly, immunohistochemistry was used to show the almost complete loss of axonal continuity, the presence of axonal end-bulbs and almost total loss of axons in the at- 

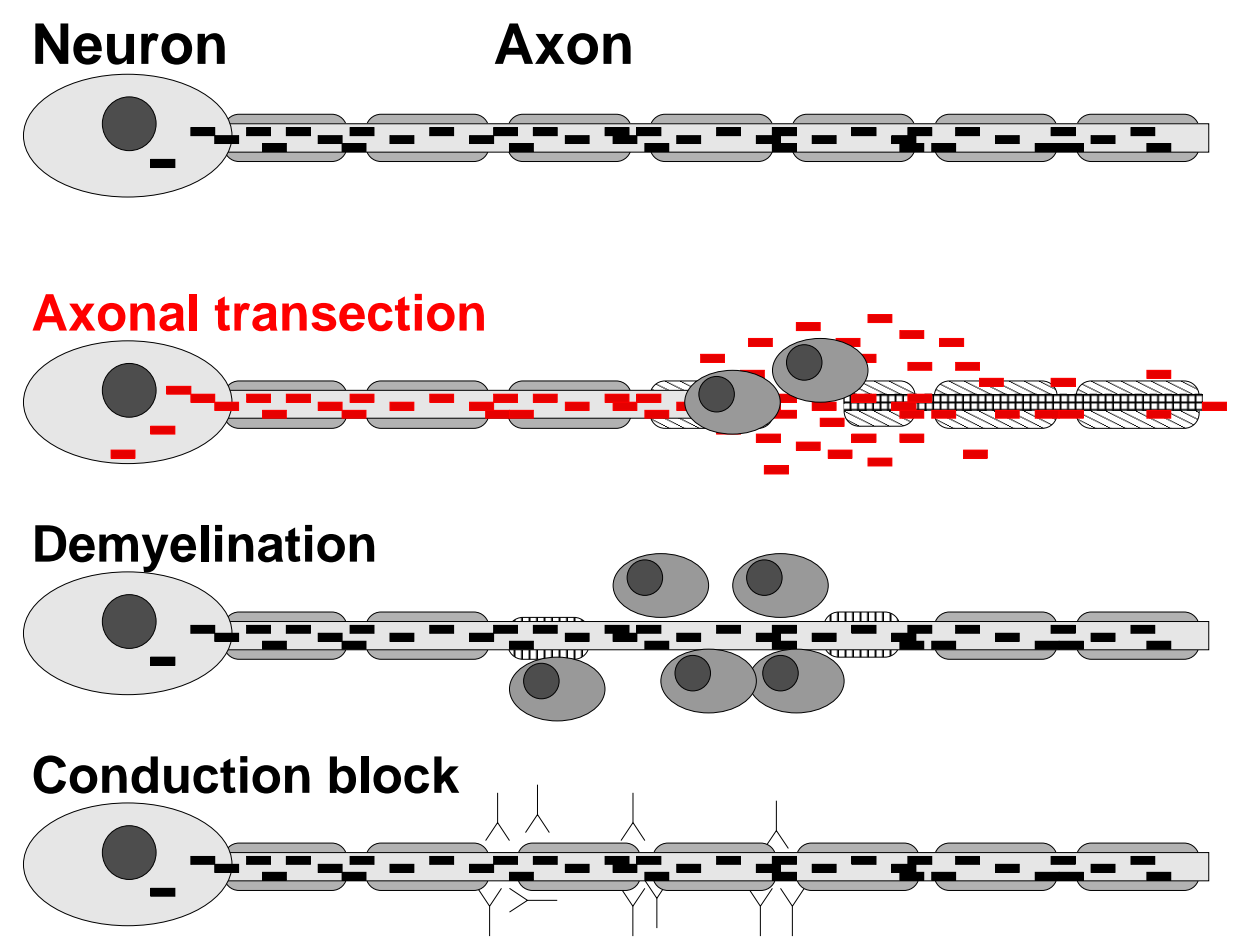

Figure 11: Neurofilaments are released into the extracellular fluid during axonal disintegration following axonal injury. Conduction block (e.g. by anti-NfH autoantibodies [111]) and demyelination are potentially reversible whilst axonal loss is not (adapted with permission from [11]). 
(A)

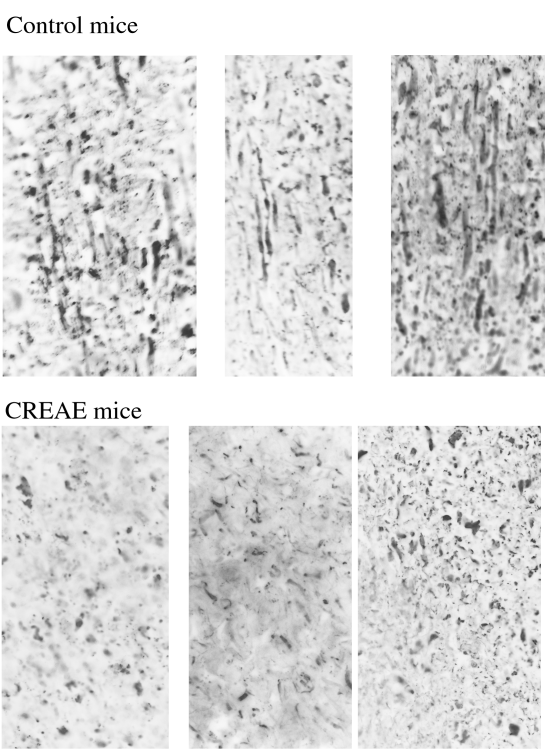

(B)

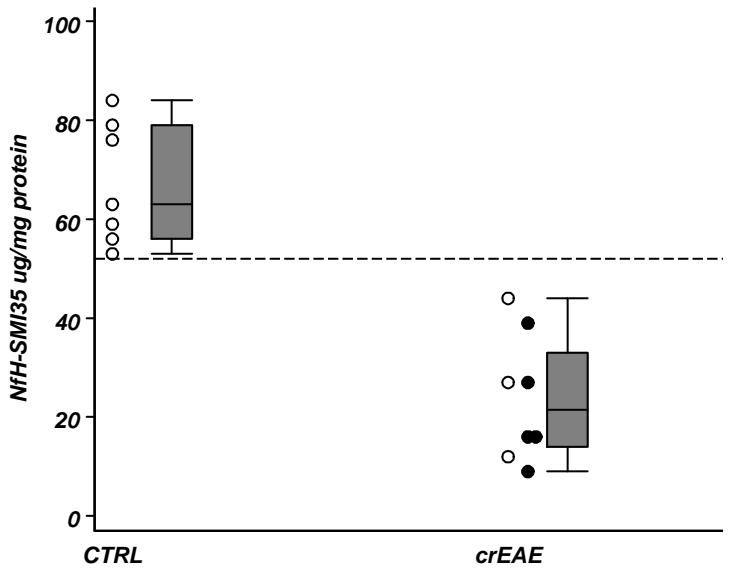

Figure 12: (A) Immunocytochemistry on longitudinal fresh frozen spinal cord sections of 3 control and 3 CREAE animals (x40). NfH staining in white matter. Axonal tracts can be followed in control but not in CREAE animals. The staining in CREAE animals is less intense and many axonal end-bulbs are seen. (B) Mice spinal cord tissue homogenates. Scatter and box-whisker plot for $\mathrm{NfH}^{S M I 35}$ (ng/mg protein). Figure adapted with permission from [142].

rophied spinal cords from CREAE mice (Figure 12 A). Secondly, analysis of this spinal cord tissue homogenate using an ELISA technique showed that the proportion of tissue $\mathrm{NfH}^{S M I 35}$ was significantly lower in CREAE animals compared to controls, and was consistent with axonal loss (Figure $12 \mathrm{~B})$.

Another, important advantage is that the phosphorylated Nf heavy chain can also be quantified from the blood in patients with ON and MS [119, 


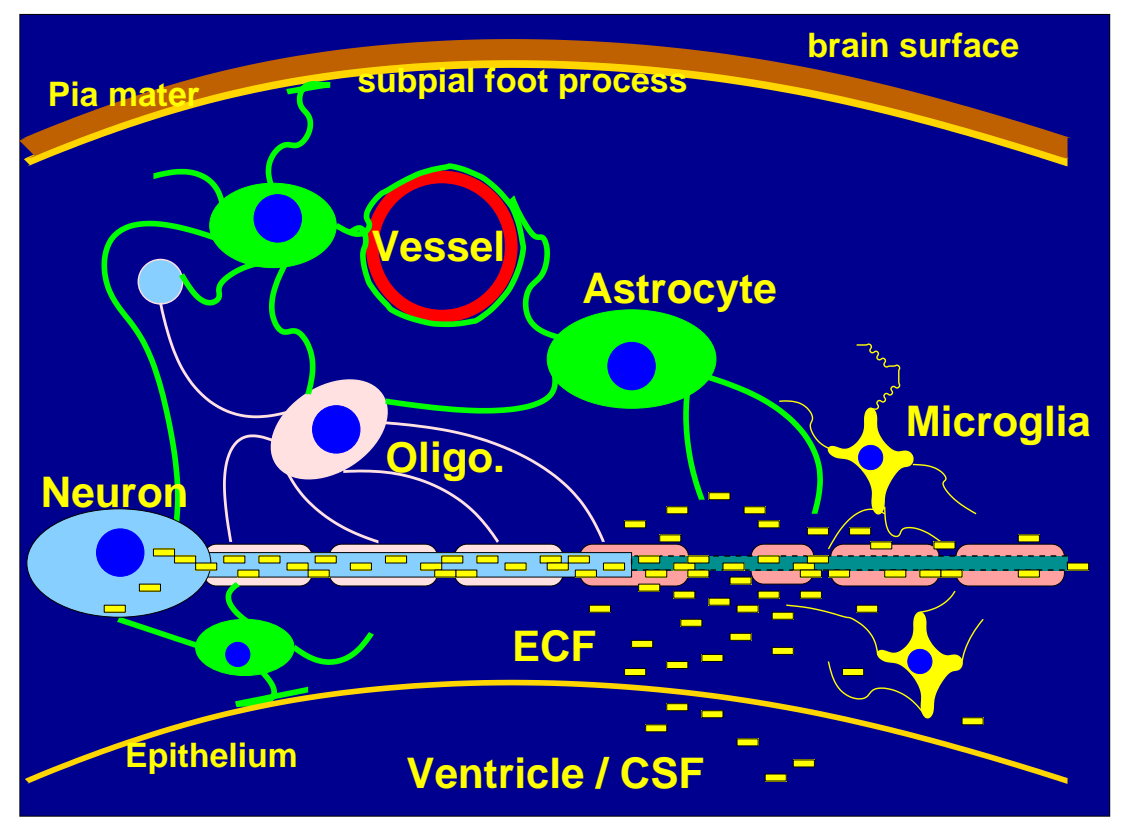

Figure 13: Biomarkers are released following brain damage. Here axonal damage is taken as an example to illustrate how neurofilaments (Nf) are released into the extracellular fluid (ECF) as the axonal membrane disintegrates. Once released into the ECF these biomarkers diffuse into the CSF from where they can be quantified following lumbar puncture. Figure reprinted with permission from [40].

$125,144]$

The challenge of sublinical disease activity for biomarkers in MS An important question to answer is how biomarkers can be used in MS to distinguish a recent insult from biomarkers released by subclinical disease activity related to older MS lesions. It may be possibile to address this difficult question by investigate post-translational modifications such as phosphorylation or glycosylation of cell-type-specific proteins.

In MS there is some evidence that the phosphorylation of $\mathrm{NfH}$ is changed 
in the MS brain [149]. This is consistent with the in vivo finding of increased CSF levels of $\mathrm{NfH}$ phosphorylation $\mathrm{NfH}$ in patients who reach the secondary progressive phase of their disease [117] and those who are more severely disabled, using the newly developed Global Multiple Sclerosis Severity Score (MSSS) [150]. Phosphorylation is only one of the many post-translational modifications biomarkers may undergo with disease.

\section{Post-translational modifications of biomarkers}

A list of cell-type specific biomarkers was presented in Table 1. Many of these biomarkers are proteins. The biochemical properties of the amino acids used to design these proteins determines the structure. For example lysine is a small amino acid allowing a protein to bend. For this reason most coiled proteins such as collagen contain a high amount of lysine. Many of these proteins undergo physiological changes called posttranslational modification (PTM). Again, the type of most PTMs are predetermined by the amino acid residues of the protein. For example the amino acids serine, threonine and tyrosine are particularly suitable for adding a phosphate atom (phosphorylation). As proteins age and get damaged and further PTMs such as oxidation occur. Most PTMs are targeted to "hot spots" in the protein. For example, oxidation and glycation are typically targeted on amino acid residues exposed at the protein surface, easily accessible to reactive molecules. 


\section{PTM — in general}

Mechanisms of covalent protein modifications comprise co-translational, post-translational and spontaneous mechanisms. The mechanisms most relevant to CSF biomarker analysis have been summarised in Table 4, and fall principally into two categories:

- enzyme-mediated, these should only occur in vivo and can be scrutinized for disease-specific signatures,

- spontaneous, which will affect proteins in vivo and in vitro and are therefore difficult to study because of artefactual modifications (see also the reference by Jiminez in the next part of the teaching course by Charlotte Teunissen).

Many of these PTMs are required to maintain normal cellular function. Under certain conditions they may, however, adversely affect protein and thus cell function, leading to disease. Additionally, non-physiological PTMs may alter the structure of a protein to such a degree that the acquired self-tolerance of the immune-system is breached and an autoimmune response results [151].

Glycosylation Simplified, glycosylation occurs mainly on five amino acids: Asp $\rightarrow$ Asp-glycan, Ser $\rightarrow$ Ser-glycan, Thr $\rightarrow$ Thr-glycan, Hyl $\rightarrow$ Hyl-glycan, Hyp $\rightarrow$ Hypglycan. In humans $\mathrm{N}$ - and $\mathrm{O}-$ glycosylation have been described. Cglycosylation has not yet been described in humans, but is known to occur in bacteria. N-glycosylation occurs at the amino-group of Asn. Oglycosylation occurs at the hydroxy-group of Thr, Ser, hydroxylysine (Hyl) 
Table 4: Mechanisms of in vivo and in vitro post-translational modifications (PTM) relevant for CSF biomarker analysis.

\begin{tabular}{lll}
\hline Mechanism & in vitro & in vivo \\
\hline Glycosylation & no & yes \\
Phosphorylation \& Dephosphorylation & no & yes \\
Citrullination & no & yes \\
N-terminal modifications & no & yes \\
C-terminal modifications & no & yes \\
Deamidation & yes & yes \\
Cross-linking & yes & yes \\
Oxidation & yes & yes \\
Nitrosylation & yes & yes \\
Glycation & yes & yes \\
Isomerisation & yes & yes \\
Racemisation & yes & yes \\
Proteolysis/Clevage & yes & yes \\
\hline
\end{tabular}

and hydroxyproline (Hyp). Proteinglycosylation is central to a range of immune processes. Altered protein glycosylation may trigger an autoimmuneresponse [151]. Glycosylation may affect charge and susceptibility to proteolysis.

Phosphorylation \& Dephosphorylation Phosphorylation is essential for intracellular signaling. A range of kinases have been described, far exceeding the scope of this teaching course (for selected reviews see references $[152,153,154,155,156,157,158,159,160,161,162,163,164])$. Phosphorylation affects manly three aminoacids: $\operatorname{Thr} \rightarrow \operatorname{Thr}(\mathrm{P}), \mathrm{Ser} \rightarrow \operatorname{Ser}(\mathrm{P})$ or $\operatorname{Tyr} \rightarrow \operatorname{Tyr}(\mathrm{P})$. It affects protein charge (more positive), molecular weight (heavier) and susceptibility to proteases (more stable with increased phosphorylation). Proteins can be immunogenic dependent on their phosphorylation status $[165,151]$. 
There is data demonstrating that the affinity of Ser to phosphate is so high that it may occur in vitro. However, these experiments have been performed in solutions containing a non-physiolgically high amount of phosphate. It is thought to be unlikely that spontaneous phosphorylation of proteins occurs to a significant degree in the CSF in vitro, because of the energy barrier.

Citrullination $\operatorname{Arg} \rightarrow$ Cit. Citrullination (synonymous: peptidylarginine deimination or just deimination) affects charge and susceptibility to proteolysis. The reaction is catalysed by peptidyl arginine deaminases in a $\mathrm{Ca}-$ dependent manner [166].

Deamidation Asn $\rightarrow$ Asp, Gln $\rightarrow$ Glu and peptide bond hydrolysis, all of which affect protein charge and may also affect susceptibility to proteolysis. The reaction is catalysed by tissue transglutaminase (TTG) in a $\mathrm{Ca}-$ dependent manner. A range of autoantigens are substrates to tTG, the most popular being gliadin in coeliac disease [167].

Isomerisatoin Asp $\rightarrow$ isoAsp, GLx $\rightarrow$ isoGly. Whilst susceptibility to proteolysis is always affected; the charge will only change if the modified residue is formed from Gln.

Racemisation Axs $\rightarrow$ D-Asp (D-isoAsp), Glx $\rightarrow$ DGlu (D-isoGlu). Occasionally also other residues such as Ala, Ser, Thr, etc. may racemise. Again susceptibility to proteolysis is always affected, charge will only change 
if the modified residue is formed from Gln or Asn.

Glycation Formation of advanced glycation end products (AGEs). The complex reactions leading to AGEs are caused by protein condensation, re-arrangement and fragmentation occurring in concentrated sugar solutions. Cross-links may occur (pentosidine, crossline, imidazolium, etc.), Lys $\rightarrow$ Amadori products, etc. Many AGEs are unstable and some are immunogenic [151]. Antibodies against AGE modified low density lipoprotein (LDL) have been demonstrated in patients with type I diabetes [168]. Protein charge and susceptibility to proteolysis can be changed.

Oxidation The principal reactions are those of: Met $\rightarrow$ Met-sulphoxide, lysine $\rightarrow$ glycoxidation \& lipoxidation products, Tyr $\rightarrow$ ortho-Tyr chloroTyr, nitroTyr, Pro \& Arg $\rightarrow$ Glu \& Glu-semialdehyde. Protein charge and susceptibility to proteolysis are changed.

Enzymes involved in oxidative damage are nitric oxide synthethase (NOS), cyclo-oxygenase (COX), mono-amine oxidase B (MAO-B) [169]. The spectrum of oxidative stress related biomarkers in MS has recently been reviewed in detail [42]. Spontaneous oxidation occurs with ionisading radiation, reduction of metal ions $(\mathrm{Fe}(\mathrm{II}), \mathrm{Cu}(\mathrm{I}))$ or chemical compounds. Oxidating compounds such as free radicals and are commonly known as reactive oxygen species (ROS).

Nitrosylation S-nitrosylation (S-nitrosation) of the thiol side-chain of cystein with NO affects almost all proteins. 
Cross-linking Cross-linking and formation of bityrosin (S-S cross-links) happens with oxidation. There is also spontaneous formation of Cystine (-CH2-S-S-CH2-) disulfides, again particularly under oxidasing conditions. There are a number of further cross-links not summarised here.

$\mathrm{N}$-terminal modifications In humans the $\mathrm{N}$-terminus is frequently $\mathrm{N}$ acetyl "blocked" and common residues are: Ala, Ser, Met, Gly or Thr. Enzymatic removal of these residues is possible.

C-terminal modifications Amidation of the $\mathrm{C}$-terminus is common. Glycine is a frequent donor for the amide. Other mechanisms are methylation and isoprenylation for GPI anchors and ADP-dependent ribosylation of C-terminal Lys.

Proteolysis The CSF is a body fluid rich in proteases, therefore proteins susceptible to proteolysis are quickly degraded. Generally phosphorylation of proteins protects to a certain degree from proteolysis. One example is the stability of the different neurofilament proteins, with NfL being less stable in the CSF than the phosphorylated form of $\mathrm{NfH}[170,171,172$, $173,174,131]$. This may be one of the reasons why the stoichemistry of phosphorylated $\mathrm{NfH}$ to $\mathrm{NfL}$ in the CSF was found to be 1:1.6 instead of the expected ratio of 1:3 (see poster \#241, this ECTRIMS meeting).

Analysis of PTMs At present there is no simple method available detect all PTMs for any selected biomarker. In future, with the advent of highly 
sensitive mass-spectroscopy, this may change.

Pitfalls There are a number of analytical pitfalls, but probably the most important one is related to sample collection and storage, both of which

need to be standardised. One example is the cleavage of cystatin $C$ $[175,176]$. Charlotte Teunissen dedicated a whole section to the current problems in CSF research (see page 2 in her manual).

\section{PTM — in autoimmunity general}

There is evidence that autoimmunity plays an important role in the pathophysiology of MS $[177,178]$.

PTMs of proteins associated with an autoimmune response in some diseases have been summarised in Table 5 .

Attempts have been made to characterise further the relationship between the cellular and humoral immune system and the antigens mentioned. For a summary of these studies see Table 6 . Those studies provide evidence that PTMs may be of relevance in the development of autoimmunity.

\section{PTM - in MS}

Is MS a post-translational disease? 
Table 5: PTM of proteins associated with autoimmune response (Adapted and updated from reference [151]). $M S=$ multiple sclerosis, $R A=$ rheumatoid arthritis, SLE = systemic lupus erythematosus.

\begin{tabular}{|c|c|c|c|}
\hline Protein & Disease/model & PTM & Reference \\
\hline MBP & $\mathrm{MS} / \mathrm{EAE}$ & $\begin{array}{l}\text { Acetylation, ADP- } \\
\text { ribosylation, Citrul- } \\
\text { lination, Deamina- } \\
\text { tion, Isomerisatoin, } \\
\text { Methylation, Phos- } \\
\text { phorylation }\end{array}$ & {$[179,180,151,181,166]$} \\
\hline$\alpha$ B-crystallin & MS/EAE & $\begin{array}{l}\text { Citrullination, Iso- } \\
\text { merisation, Phospho- } \\
\text { rylation }\end{array}$ & {$[182,183,184]$} \\
\hline Type II Collagen & $\mathrm{RA} / \mathrm{CIA}$ & $\begin{array}{l}\text { Glycosylation, Hy- } \\
\text { droxylation }\end{array}$ & [185] \\
\hline Fibrin & RA & Citrullination & [186] \\
\hline Fillagrin & RA & Citrullination & [187] \\
\hline Vimentin & RA & Citrullination & {$[188,189]$} \\
\hline $\lg G$ & RA & $\begin{array}{l}\text { Isomerisation, Glyca- } \\
\text { tion }\end{array}$ & {$[190,151]$} \\
\hline Insulin & Type I Diabetes & $\begin{array}{l}\text { Deamidation, Iso- } \\
\text { merisation }\end{array}$ & [191] \\
\hline GAD & Type I Diabetes & Oxidation & [192] \\
\hline Histone H2B & SLE & $\begin{array}{l}\text { Isomerisation, Trans- } \\
\text { glutamination }\end{array}$ & {$[193,194]$} \\
\hline SnRNP D & SLE & Isomerisation & [195] \\
\hline SnRNP 70k & SLE & Phosphorylation & [196] \\
\hline
\end{tabular}


Table 6: Cellular and humoral immunological response of PTMs associated with the autoimmnue diseases listed in Table 6. (Modified from reference [151]. $N D=$ not determined, $C / A=$ collagen induced arthritis.)

\begin{tabular}{|c|c|c|c|c|c|}
\hline \multirow[t]{2}{*}{ PTM } & \multirow[t]{2}{*}{ Protein } & \multirow[t]{2}{*}{ Disease/model } & \multicolumn{2}{|c|}{ Immune response } & \multirow[t]{2}{*}{ Reference } \\
\hline & & & TÂÂÂÂcell & B-cell & \\
\hline \multirow[t]{2}{*}{ Phosphorylation } & $\alpha \mathrm{BA \tilde {A } A \hat { A }}$ crystallin & EAE & specific & ND & [183] \\
\hline & snRNP 70 k & SLE & specific & diverse & [196] \\
\hline Glycosylation & Collagen & CIA & specific & ND & [185] \\
\hline \multirow{4}{*}{ Citrullination } & MBP & EAE & specific & diverse & [197] \\
\hline & Fibrin & RA & ND & specific & [186] \\
\hline & Fillagrin & RA & ND & specific & [187] \\
\hline & Vimentin & DR4-IE & specific & ND & [198] \\
\hline Deamidation & Gliadin & Coeliac & specific & specific & [199] \\
\hline \multirow[t]{2}{*}{ Glycation } & $\lg G$ & RA & ND & specific & [190] \\
\hline & LDL & Diabetes & specific & diverse & [200] \\
\hline \multirow[t]{2}{*}{ Isomerisation } & $\lg G$ & SLE (?) & & specific & [151] \\
\hline & SnRNP D & SLE & specific & diverse & [195] \\
\hline
\end{tabular}

\section{Citrullination}

In MS citrullination is the most studied PTM from those listed in Table 4. MS leaves a signature using citrullination on $\operatorname{MBP}[179,180,151,181]$ and GFAP [201].

MBP MBP has been particularly well investigated. Citrullination of MBP alters its conformation and interaction with other proteins and the myelin membrane $[202,203]$. The change of charge (citrullination reduces the positive charge) of MBP results in loosening of the otherwise tight compaction of the major dense line between myelin and the axon. It has therefore been speculated that MS may be a post-translational disease where "molecular negativity" may expose MBP epitopes and cause an autoimmune response [204] (see Figure 14). To think about MS as a post- 
translational disease is tempting and analogous to one approach taken for other autoimmune diseases [205, 206, 207]. However, much remains speculation as we still know too little about the aetiology of MS and ar only just getting access to the analytical tools for detailed investigation of PTMs. Nevertheless, for the interested reader Harauz and Musse have summarised in their detailed review the known effects of citrullination on MRP and mvelin stahilitv (Tahle 1 in [166])

\section{Normal Epitope MS Epitope}

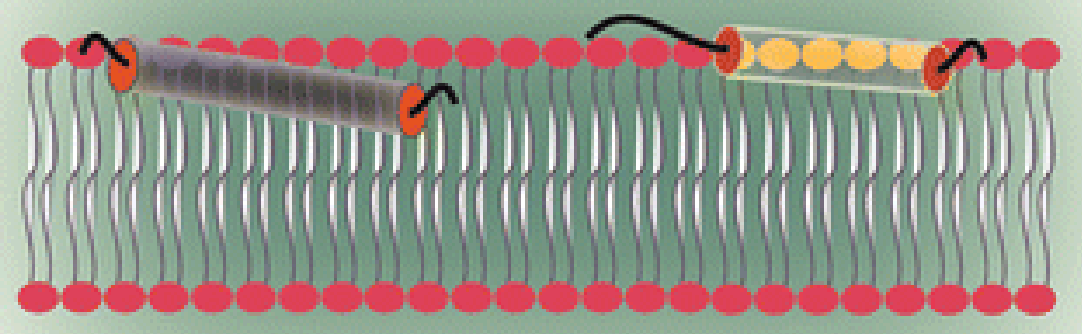

Figure 14: Molecular "negativity" may underlie MS. Musse et al. [204] examined the structural changes of MBP when the number of positively charged residues was artificially reduced, to mimic the modification which occurs in MS patients. It was found that reducing the net positive charge exposes this region of the protein and evokes a strong immune response, making it susceptible to cleavage by proteases. Although antibodies to MBP are often detected in patients with MS, just why this protein becomes so vulnerable to the immune system has remained unclear. The mechanism depicted here may explain how the body's immune system gains access to myelin antigens, and provides structural insight into a possible pathological mechanism for MS [208]. (Reproduced with permision from reference [166]).

MBP citrullination is probably also of clinical relevance. Wood and Moscarello suggested in the 80ies that there was a relationship between the severity of MS, the degree of myelin degeneration and the character- 
istics of MBP. Using cation-exchange chromatography it was shown that the citrullination of MBP was about 6.7 to 8-fold higher in severe disease, including one case of the Marburg variant, when compared to patients with milder forms of MS $[180,209]$. In other words, in normal humans about $20 \%$ of MBP is citrullinated, in chronic MS about $45 \%$ and in the case report on the Marburg variant about $80 \%[180,209]$.

Mechanisms of MBP citrullination in MS Peptidularginine deiminases (PAD or PADI, EC 3.5.3.15) are the enzymes responsible for the conversion of peptide-linked arginine to citrulline in vivo in a Ca-dependent manner. Some of the PAD isoforms were shown to be in increased in MS brain tissue by some [210, 211, 212, 213], but not by other investigators [214].

EAE Increased protein citrullination makes EAE worse [215, 216, 217, 166].

\section{Phosphorylation}

Tau An increase of tau phosphorylation in the brain tissue of rat with EAE has been shown [218, 219]. Figure 15 shows that for equal amounts of total tau (antibody tau-5) there is a relatively larger proportion of phosphorylated tau (antibodies AT8, AT100, AT-180 and 12E8) in brain tissue from rats with EAE when compared to controls. CSF studies on tau phosphoforms in MS are still lacking. The technology for these studies is available and tau phosphoforms have been studied intensively in the CSF of patients with Alzheimer's disease. It would be interesting to test whether an 
increase of tau phosphorylation is found in the CSF from patient with MS and whether this relates to disease severity/subtype. One study measured total tau and p-tau levels in the CSF of patients with MS [220], but we do not know about the ratio of p-tau/tau as an estimate for tau phosphorylation. Such a ratio would extend on previous work showing an increase of total tau in the CSF of patients with MS [118, 221, 222, 220, 223], a finding not replicated by others [224, 225].

A.

kDa EAE Ctr. EAE Ctr. kDa

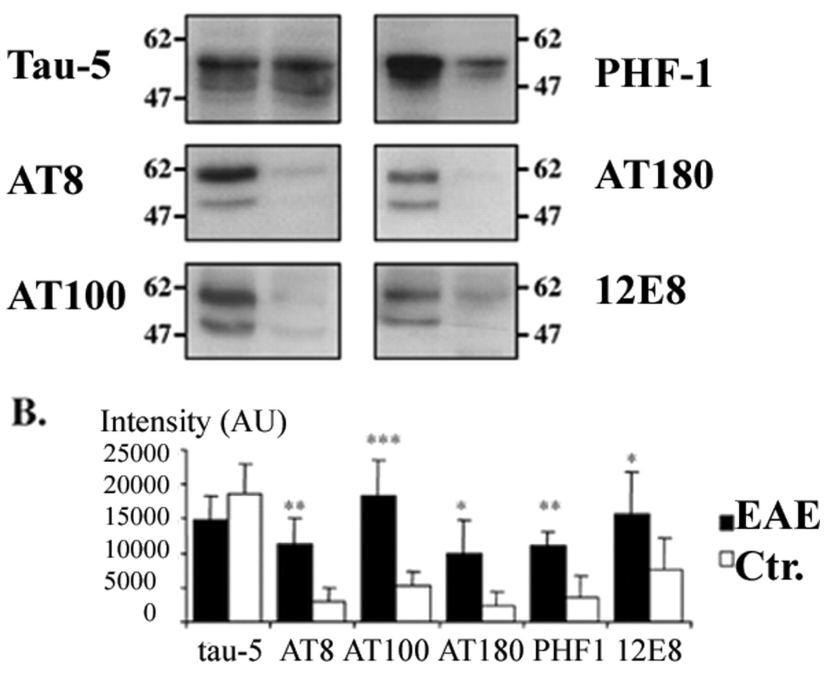

Figure 15: Hyperphosphorylation of tau in rats with EAE. A, protein lysates prepared from EAE brainstems and controls containing equal amounts of proteins were subjected to Western blot analysis with phosphorylationdependent antibodies PHF-1 (pS396/pS404), AT-8 (pS202/pT205), AT-100 (pT212/pS214), AT-180 (pT231/pS235), and 12E8 (pS262) in addition to the pan-tau antibody tau-5. B, quantitative analysis of tau expression and phosphorylation of tau epitopes in EAE and control brains. Values are mean \pm S.D., $n=5$ for each value. Three independent experiments showed similar results $\left({ }^{*}, p<0.05 ;^{* *}, p<0.01 ;^{* * *}, p<0.001\right)$. Copied from reference [219]. 
Neurofilaments An increase of $\mathrm{NfH}$ phosphorylation has been described in the CSF of patients with secondary progressive MS when compared to those with relapsing remitting disease (Figure 16) [117]. Neurofilament phosphorylation was increased about 8-fold in patients with optic neuritis compared to other neurological controls [226]. Recently a new clinical score for the severity of MS, the MS severity score (MSSS) has been developed [227]. A re-analysis of the samples from our initial study [117] showed that patients with more severe disease had an 8-fold higher degree of $\mathrm{NfH}$ phosphorylation [150].

\section{Glycosylation}

Kaj Blennow's group recently described a new ELISA which allows for the measurement of glycosolyated forms of clusterin in the CSF [228]. Figure 17 demonstrates that enzymatic deglycosylation of clusterin enhances the antibody affinity. There is no data on clusterin glycoforms in the CSF of patients with MS.

Acknowledgements The author's work described in this chapter is supported by the Dutch MS Research Foundation, the University College London Comprehensive Bio-medical Research Centre abd the Moorfields Biomedical Research Centre. 

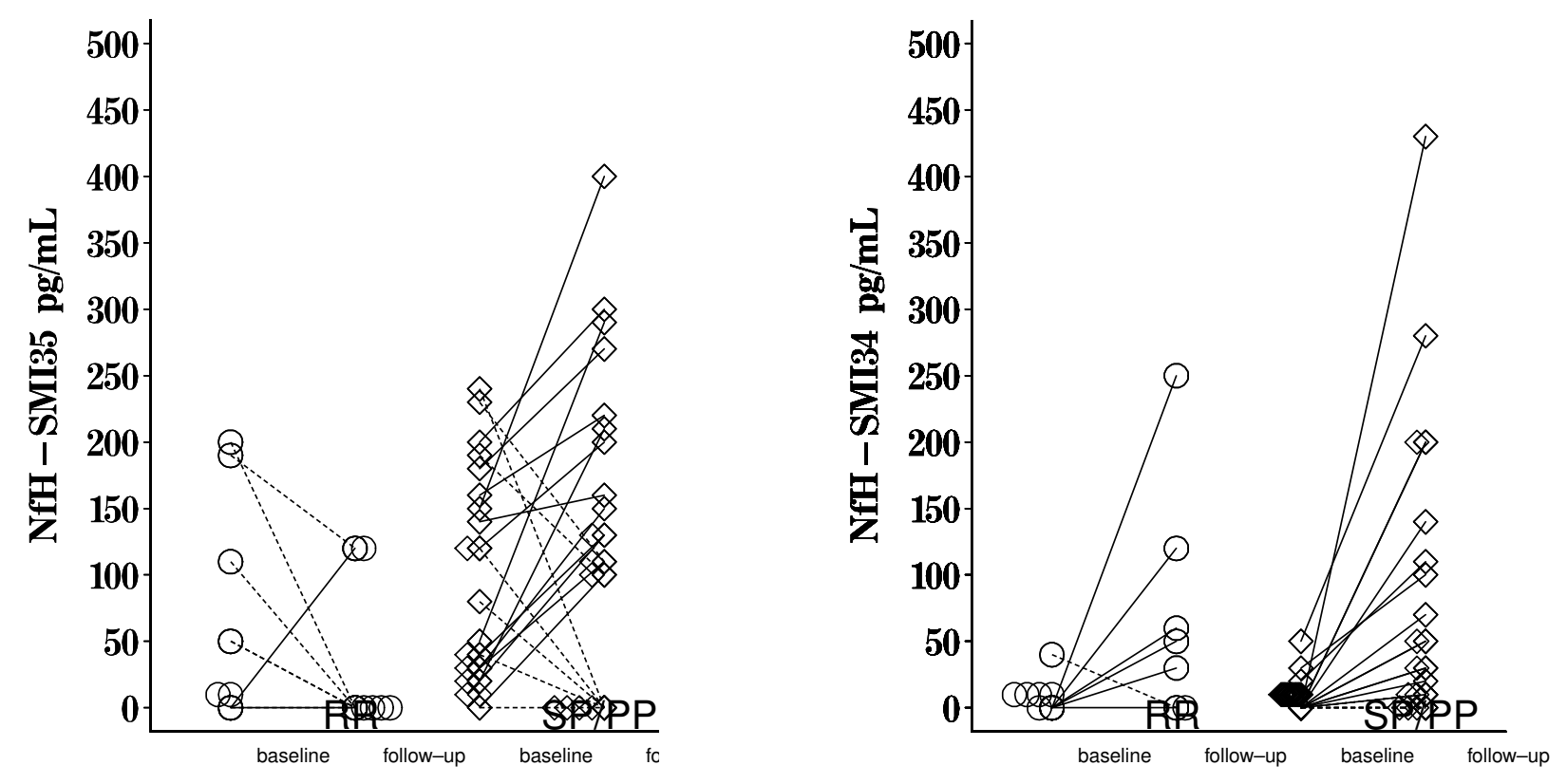

Figure 16: (A) CSF $\mathrm{NfH}^{S M I 35}$ levels in patients $R R$ (open circles) and SP/PP (diamonds) forms of MS. A significantly higher proportion of SP/PP MS patients (13/22) had increased CSF NfH ${ }^{S M I 35}$ levels between baseline and follow-up (straight lines) when compared to RR MS patients (1/7, $p<0.05$, Fisher's exact test). (B) CSF NfH ${ }^{S M I 34}$ levels in patients $R R$ (open circles) and SP/PP (diamonds) forms of MS. Figure reproduced with permission from reference [117]. 

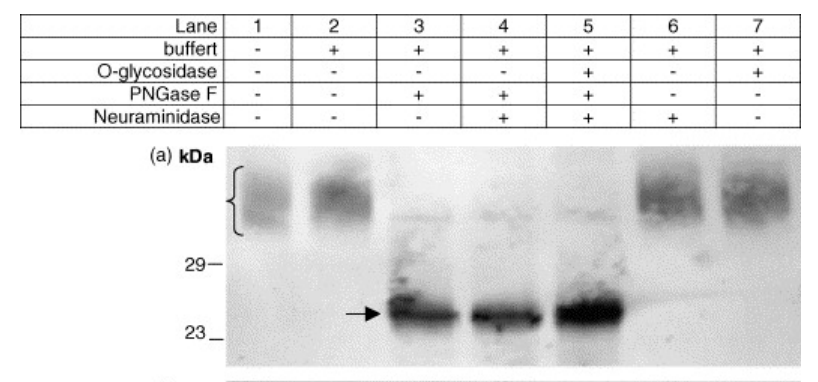

(b)

Figure 17: ${ }^{2}$ Western blot of enriched CSF clusterin enzymatically deglycosylated using the enzymes PNGase $F, O$-glycosidase, and neuraminidase as tabulated above and detected by (a) the $C-18$ and (b) the 05-354 antibody. Lanes 1 and 2: unincubated native CSF reference samples; lanes 3-7: enzymatically deglycosylated CSF samples, all incubated at $37^{\circ} \mathrm{C}$. There was a mw shift of both the $\alpha$ - (b) and $\beta$-chain (a) of CSF clusterin into not, vert, similar $\approx 25-27 \mathrm{kDa}$ (arrow) in samples deglycosylated by PNGase $F$, indicating N-linked carbohydrates being attached. No shift of clusterin was detected by the use of O-glycosidase or neuraminidase. Levels of mw marker in margin. (-) Enzyme not added and (+) enzyme added. Figure reproduced with permission from reference [228]. 


\section{References}

[1] Massimo Filippi, Maria A Rocca, Olga Ciccarelli, Nicola De Stefano, Nikos Evangelou, Ludwig Kappos, Alex Rovira, Jaume SastreGarriga, Mar Tintorè, Jette L Frederiksen, Claudio Gasperini, Jacqueline Palace, Daniel S Reich, Brenda Banwell, Xavier Montalban, Frederik Barkhof, and MAGNIMS Study Group. MRI criteria for the diagnosis of multiple sclerosis: Magnims consensus guidelines. 15(3):292-303, March 2016.

[2] Laura Dennison, Ellen McCloy Smith, Katherine Bradbury, and lan Galea. How do people with multiple sclerosis experience prognostic uncertainty and prognosis communication? a qualitative study. PloS one, 11:e0158982, 2016.

[3] Catherine Larochelle, Timo Uphaus, Alexandre Prat, and Frauke Zipp. Secondary progression in multiple sclerosis: Neuronal exhaustion or distinct pathology? Trends in neurosciences, 39:325339, May 2016.

[4] Martin Stangel, Sten Fredrikson, Edgar Meinl, Axel Petzold, Olaf StÃ $14 v e$, and Hayrettin Tumani. The utility of cerebrospinal fluid analysis in patients with multiple sclerosis. 9:267-276.

[5] Jens Kuhle. Comment: "if you can't measure it, you can't improve it" (lord kelvin). Neurology, 87:1335, September 2016. 
[6] Axel Petzold. Isolated, relapsing and progressive demyelinating diseases of the central nervous system. 255 Suppl 6:69-76.

[7] Micha Mandel, Francois Mercier, Benjamin Eckert, Peter Chin, and Rebecca A Betensky. Estimating time to disease progression comparing transition models and survival methods-an analysis of multiple sclerosis data. Biometrics, 69:225-234, March 2013.

[8] Axel Petzold, Robert Bowser, Paolo Calabresi, Henrik Zetterberg, and Bernard MJ Uitdehaag. Biomarker time out.

[9] Axel Petzold. Neurodegeneration and multiple sclerosis. In Neurodegenerative Diseases, pages 227-245. Springer.

[10] Manuel A. Friese, Benjamin Schattling, and Lars Fugger. Mechanisms of neurodegeneration and axonal dysfunction in multiple sclerosis. pages 225-238.

[11] A Petzold. Neurofilament phosphoforms: surrogate markers for axonal injury, degeneration \& loss. J Neurol Sci, 233:183-198, 2005.

[12] Brit Fitzner, Michael Hecker, and Uwe Klaus Zettl. Molecular biomarkers in cerebrospinal fluid of multiple sclerosis patients. 14(10):903-913.

[13] R. Martin, B. Bielekova, R. Hohlfeld, and U. Utz. Biomarkers in multiple sclerosis. Dis Markers, 22:183-105, 2006. 
[14] L.M. McShane, D.G. Altman, W. Sauerbrei, S.E. Taube, M. Gion, and G.M. Clark. REporting recommendations for tumor MARKer prognostic studies (REMARK). 100:229-235.

[15] JF Kurtzke. Rating neurological impairment in multiple sclerosis: an expanded disability status scale (EDSS). Neurology, 33:1444-1452, 1983.

[16] B. M J Uitdehaag, H. J. AdÃ̈r, T. J A Roosma, V. de Groot, N. F. Kalkers, and C. H. Polman. Multiple sclerosis functional composite: impact of reference population and interpretation of changes. 8(5):366-371.

[17] J. Kuhle and A Petzold. What makes a prognostic biomarker in cns diseases: strategies for targeted biomarker discovery? part 1: acute and monophasic diseases. 5:333-346.

[18] J. Kuhle and A Petzold. What makes a prognostic biomarker in cns diseases: strategies for targeted biomarker discovery? part 2: chronic progressive and relapsing diseases. 5:393-410.

[19] Mehtap Bacioglu, Luis F Maia, Oliver Preische, Juliane Schelle, Anja Apel, Stephan A Kaeser, Manuel Schweighauser, Timo Eninger, Marius Lambert, Andrea Pilotto, Derya R Shimshek, Ulf Neumann, Philipp J Kahle, Matthias Staufenbiel, Manuela Neumann, Walter Maetzler, Jens Kuhle, and Mathias Jucker. Neurofilament light chain in blood and csf as marker of disease progression in mouse mod- 
els and in neurodegenerative diseases. Neuron, 91:494-496, July 2016.

[20] Richard Macrez, Peter K Stys, Denis Vivien, Stuart A Lipton, and Fabian Docagne. Mechanisms of glutamate toxicity in multiple sclerosis: biomarker and therapeutic opportunities. The Lancet Neurology, 15(10):1089-1102, 2016.

[21] Marloes Hagens, Bart van Berckel, and Frederik Barkhof. Novel mri and pet markers of neuroinflammation in multiple sclerosis. Current opinion in neurology, 29(3):229-236, 2016.

[22] Axel Petzold, Johannes F de Boer, Sven Schippling, Patrik Vermersch, Randy Kardon, Ari Green, Peter A Calabresi, and Chris Polman. Optical coherence tomography in multiple sclerosis: a systematic review and meta-analysis. 9(9):921-932.

[23] Elena H. Martinez-Lapiscina, Sam Arnow, James A. Wilson, Shiv Saidha, Jana Lizrova Preiningerova, Timm Oberwahrenbrock, Alexander U. Brandt, Luis E. Pablo, Simone Guerrieri, Ines Gonzalez, Olivier Outteryck, Ann-Kristin Mueller, Phillip Albrecht, Wesley Chan, Sebastian Lukas, Lisanne J. Balk, Clare Fraser, Jette L. Frederiksen, Jennifer Resto, Teresa Frohman, Christian Cordano, Irati Zubizarreta, Magi Andorra, Bernardo Sanchez-Dalmau, Albert Saiz, Robert Bermel, Alexander Klistorner, Axel Petzold, Sven Schippling, Fiona Costello, Orhan Aktas, Patrick Vermersch, Celia OrejaGuevara, Giancarlo Comi, Letizia Leocani, Elena Garcia-Martin, 
Friedemann Paul, Eva Havrdova, Elliot Frohman, Laura J. Balcer, Ari J. Green, Peter A. Calabresi, Pablo Villoslada, and I. M. S. V. I. S. U. A. L consortium . Retinal thickness measured with optical coherence tomography and risk of disability worsening in multiple sclerosis: a cohort study. 15:574-584.

[24] Xavier Giffroy, Nathalie Maes, Adelin Albert, Pierre Maquet, JeanMichel Crielaard, and Dominique Dive. Do evoked potentials contribute to the functional follow-up and clinical prognosis of multiple sclerosis? Acta Neurologica Belgica, pages 1-7, 2016.

[25] Axel Petzold and Gordon T. Plant. Diagnosis and classification of autoimmune optic neuropathy. 13:539-545.

[26] Nadia Aalling Jessen, Anne Sofie Finmann Munk, Iben Lundgaard, and Maiken Nedergaard. The glymphatic system: a beginnerâs guide. Neurochemical research, 40(12):2583-2599, 2015.

[27] C. Nilsson, F. Stahlberg, C. Thomsen, O. Henriksen, M. Herning, and C. Owman. Circadian variation in human cerebrospinal fluid production measured by magnetic resonance imaging. Am J Physiol, 262:R20-4, 1992.

[28] Vadim Ratner, Yi Gao, Hedok Lee, Maikan Nedergaard, Helene Benveniste, and Allen R Tannenbaum. Cerebrospinal fluid and interstitial fluid motion via the glymphatic pathway modelled by optimal mass transport. bioRxiv, page 043281, 2016. 
[29] Axel Petzold, Martin M Tisdall, Armand R Girbes, Lillian Martinian, Maria Thom, Neil Kitchen, and Martin Smith. In vivo monitoring of neuronal loss in traumatic brain injury: a microdialysis study. 134(Pt 2):464-483.

[30] Norman R Saunders, Mark D Habgood, Kjeld Møllgård, and Katarzyna M Dziegielewska. The biological significance of brain barrier mechanisms: help or hindrance in drug delivery to the central nervous system? F1000Research, 5, 2016.

[31] Steven M LeVine. Albumin and multiple sclerosis. BMC neurology, 16(1):1, 2016.

[32] Bethany Young, Atul Kalanuria, Monisha Kumar, Kathryn Burke, Ramani Balu, Olivia Amendolia, Kyle McNulty, BethAnn Marion, Brittany Beckmann, Lauren Ciocco, et al. Cerebral microdialysis. Critical care nursing clinics of North America, 28(1):109-124, 2016.

[33] Jeffrey J lliff, Minghuan Wang, Yonghong Liao, Benjamin A Plogg, Weiguo Peng, Georg A Gundersen, Helene Benveniste, G Edward Vates, Rashid Deane, Steven A Goldman, et al. A paravascular pathway facilitates csf flow through the brain parenchyma and the clearance of interstitial solutes, including amyloid $\beta$. Science translational medicine, 4(147):147ra111-147ra111, 2012.

[34] Shannon R Hinson, Vanda A Lennon, and Sean J Pittock. Autoimmune aqp4 channelopathies and neuromyelitis optica spectrum disorders. 133:377-403, 2016. 
[35] Bernhard Hemmer, Martin Kerschensteiner, and Thomas Korn. Role of the innate and adaptive immune responses in the course of multiple sclerosis. 14(4):406-419.

[36] A. Petzold. Retinal glymphatic system: an explanation for transient retinal layer volume changes? 139:2816-2826, 2016.

[37] Peter Wostyn, Veva De Groot, Debby Van Dam, Kurt Audenaert, Hanspeter Esriel Killer, and Peter Paul De Deyn. Age-related macular degeneration, glaucoma and alzheimerâs disease: amyloidogenic diseases with the same glymphatic background? Cellular and Molecular Life Sciences, 73(22):4299-4301, 2016.

[38] Richard F Spaide. Retinal vascular cystoid macular edema: Review and new theory. Retina, 36(10):1823-1842, 2016.

[39] Johanna Gaiottino, Niklas Norgren, Ruth Dobson, Joanne Topping, Ahuva Nissim, Andrea Malaspina, Jonathan P. Bestwick, Andreas U. Monsch, Axel Regeniter, Raija L. Lindberg, Ludwig Kappos, David Leppert, Axel Petzold, Gavin Giovannoni, and Jens Kuhle. Increased neurofilament light chain blood levels in neurodegenerative neurological diseases. 8(9):e75091.

[40] A Petzold. Biomarker for early diagnosis of Alzheimer's disease, chapter The CSF analysis in dementia, pages 123-156. NOVA Science Publishers, INc., 1 edition.

[41] Axel Petzold. Glial fibrillary acidic protein is a body fluid biomarker for glial pathology in human disease. 1600:17-31. 
[42] Richard Ibitoye, Kevin Kemp, Claire Rice, Kelly Hares, Neil Scolding, and Alastair Wilkins. Oxidative stress-related biomarkers in multiple sclerosis: a review. Biomarkers in Medicine, 10(8):889-902, 2016.

[43] A. Wilkins and N. Scolding. Protecting axons in multiple sclerosis. 14(8):1013-1025.

[44] D. Miller, F. Barkhof, X. Montalban, A. Thompson, and M. Filippi. Clinically isolated syndromes suggestive of multiple sclerosis, part I: natural history, pathogenesis, diagnosis, and prognosis. Lancet Neurol, 4(5):281-8, 2005.

[45] FD Lublin and SC Reingold. Defining the clinical course of multiple sclerosis: results of an international survey National Multiple Sclerosis Society (USA) Advisory Committee on Clinical Trials of New Agents in Multiple Sclerosis. Neurology, 46:907-911, 1996.

[46] C Confavreux, S Vukusic, and P Adeleine. Early clinical predictors and progression of irreversible disability in multiple sclerosis: an amnesic process. 126:770-782.

[47] Axel Petzold, Sui Wong, and Gordon T Plant. Autoimmunity in visual loss. Handb Clin Neurol, 133:353-376, 2016.

[48] Ian Galea, Mark S. Freedman, and Edward J. Thompson. Cerebrospinal fluid analysis in the 2010 revised mcdonald's multiple sclerosis diagnostic criteria. 70(1):183; author reply 183-183; author reply 184 . 
[49] Hayrettin Tumani, Florian Deisenhammer, Gavin Giovannoni, Ralf Gold, Hans-Peter Hartung, Bernhard Hemmer, Reinhard Hohlfeld, Markus Otto, Martin Stangel, Brigitte Wildemann, and Uwe K. Zettl. Revised mcdonald criteria: The persisting importance of cerebrospinal fluid analysis.

[50] Chris H. Polman and for the International Panel on Diagnosis of Multiple Sclerosis . Reply. Ann Neurol, Jun 2011.

[51] Philipp Schwenkenbecher, Anastasia Sarikidi, Ulrich Wurster, Paul Bronzlik, Kurt-Wolfram SÃ $\frac{1}{4} \mathrm{hs}$, Peter Raab, Martin Stangel, Refik Pul, and Thomas Skripuletz. Mcdonald criteria 2010 and 2005 compared: Persistence of high oligoclonal band prevalence despite almost doubled diagnostic sensitivity. International journal of molecular sciences, 17(9):1592, 2016.

[52] André M Huss, Steffen Halbgebauer, Patrick Öckl, Corinna Trebst, Annette Spreer, Nadja Borisow, Andrea Harrer, Isabel Brecht, Bettina Balint, Oliver Stich, et al. Importance of cerebrospinal fluid analysis in the era of mcdonald 2010 criteria: a german-austrian retrospective multicenter study in patients with a clinically isolated syndrome. Journal of Neurology, 263(12):2499-2504, 2016.

[53] Chris H. Polman, Stephen C. Reingold, Brenda Banwell, Michel Clanet, Jeffrey A. Cohen, Massimo Filippi, Kazuo Fujihara, Eva Havrdova, Michael Hutchinson, Ludwig Kappos, Fred D. Lublin, Xavier Montalban, Paul O'Connor, Magnhild Sandberg-Wollheim, 
Alan J. Thompson, Emmanuelle Waubant, Brian Weinshenker, and Jerry S. Wolinsky. Diagnostic criteria for multiple sclerosis: 2010 revisions to the mcdonald criteria. 69(2):292-302.

[54] C. H. Polman, S. C. Reingold, G. Edan, M. Filippi, H. P. Hartung, L. Kappos, F. D. Lublin, L. M. Metz, H. F. McFarland, P. W. O'Connor, M. Sandberg-Wollheim, A. J. Thompson, B. G. Weinshenker, and J. S. Wolinsky. Diagnostic criteria for multiple sclerosis: 2005 revisions to the "McDonald Criteria". Ann Neurol, 58:840-6, 2005.

[55] WI McDonald, A Compston, G Edan, et al. Recommended diagnostic criteria for multiple sclerosis: guidelines from the International Panel on the diagnosis of multiple sclerosis. 50:121-127.

[56] D. F. Keren. Optimizing detection of oligoclonal bands in cerebrospinal fluid by use of isoelectric focusing with IgG immunoblotting. Am J Clin Pathol, 120:649-51, 2003.

[57] C. E. Teunissen, A. Petzold, J. L. Bennett, F. S. Berven, L. Brundin, M. Comabella, D. Franciotta, J. L. Frederiksen, J. O. Fleming, R. Furlan, R. Q. Hintzen, S. G. Hughes, M. H. Johnson, E. Krasulova, J. Kuhle, M. C. Magnone, C. Rajda, K. Rejdak, H. K. Schmidt, V. van Pesch, E. Waubant, C. Wolf, G. Giovannoni, B. Hemmer, H. Tumani, and F. Deisenhammer. A consensus protocol for the standardization of cerebrospinal fluid collection and biobanking. 73(22):1914-1922. 
[58] M.S. Freedman, E.J. Thompson, F. Deisenhammer, G. Giovannoni, G. Grimsley, G. Keir, S. Ohman, M.K. Racke, M. Sharief, C.J. Sindic, F. Sellebjerg, and W.W. Tourtellotte. Recommended standard of cerebrospinal fluid analysis in the diagnosis of multiple sclerosis: a consensus statement. 62:865-870.

[59] V. Abraira, J. C. Alvarez-Cermeño, R. Arroyo, C. Cámara, B. Casanova, S. Cubillo, C. de Andrés, C. Espejo, Fernández, et al. Utility of oligoclonal IgG band detection for ms diagnosis in daily clinical practice. 371(1-2):170-173.

[60] Axel Petzold. Intrathecal oligoclonal igg synthesis in multiple sclerosis. 262(1-2):1-10.

[61] Laura Lovato, Simon N. Willis, Scott J. Rodig, Tyler Caron, Stefany E. Almendinger, Owain W. Howell, Richard Reynolds, Kevin C. O'Connor, and David A. Hafler. Related b cell clones populate the meninges and parenchyma of patients with multiple sclerosis. 134(Pt 2):534-541.

[62] Christopher Harp, Jane Lee, Doris Lambracht-Washington, Elizabeth Cameron, Gregory Olsen, Elliot Frohman, Michael Racke, and Nancy Monson. Cerebrospinal fluid b cells from multiple sclerosis patients are subject to normal germinal center selection. 183(12):189-199.

[63] Michael K. Racke. The role of b cells in multiple sclerosis: rationale for b-cell-targeted therapies. 21 Suppl 1:S9-S18. 
[64] Birgit Obermeier, Reinhard Mentele, Joachim Malotka, Josef Kellermann, Tania KÃ $14 m p f e l$, Hartmut Wekerle, Friedrich Lottspeich, Reinhard Hohlfeld, and Klaus Dornmair. Matching of oligoclonal immunoglobulin transcriptomes and proteomes of cerebrospinal fluid in multiple sclerosis. 14(6):688-693.

[65] Nancy L. Monson, Hans-Peter Brezinschek, Ruth I. Brezinschek, Angela Mobley, Gwen K. Vaughan, Elliot M. Frohman, Michael K. Racke, and Peter E. Lipsky. Receptor revision and atypical mutational characteristics in clonally expanded $b$ cells from the cerebrospinal fluid of recently diagnosed multiple sclerosis patients. 158(1-2):170-181.

[66] Y. Qin, P. Duquette, Y. Zhang, P. Talbot, R. Poole, and J. Antel. Clonal expansion and somatic hypermutation of $\mathrm{V}(\mathrm{H})$ genes of $\mathrm{B}$ cells from cerebrospinal fluid in multiple sclerosis. J Clin Invest, 102:1045-50, 1998.

[67] B. Arneth and F. Birklein. High sensitivity of free lambda and free kappa light chains for detection of intrathecal immunoglobulin synthesis in cerebrospinal fluid. 119(1):39-44.

[68] J. Bednárová, P. Stourac, and P. Adam. Relevance of immunological variables in neuroborreliosis and multiple sclerosis. 112(2):97-102.

[69] A. Bourahoui, J. De Seze, R. Guttierez, B. Onraed, B. Hennache, D. Ferriby, T. Stojkovic, and P. Vermersch. Csf isoelectrofocusing in 
a large cohort of ms and other neurological diseases. 11(8):525529.

[70] Christiane Caudie, Al Medhi Birouk, Julien Bancel, DaniÃ"le Claudy, Laurence Gignoux, Sandra Vukusic, and Christian Confavreux. Cytoimmunological profile of cerebrospinal fluid in diagnosis of multiple sclerosis. 53(2):68-74.

[71] M. Falip, M. Tintoré, R. Jardí, I. Duran, H. Link, and X. Montalbán. [clinical usefulness of oligoclonal bands]. 32(12):1120-1124.

[72] Alexandre S. Fortini, Elizabeth L. Sanders, Brian G. Weinshenker, and Jerry A. Katzmann. Cerebrospinal fluid oligoclonal bands in the diagnosis of multiple sclerosis. isoelectric focusing with $\lg G$ immunoblotting compared with high-resolution agarose gel electrophoresis and cerebrospinal fluid IgG index. 120(5):672-675.

[73] D. Franciotta, E. Zardini, R. Bergamaschi, L. M. Grimaldi, L. Andreoni, and V. Cosi. Analysis of chlamydia pneumoniae-specific oligoclonal bands in multiple sclerosis and other neurologic diseases. 112(4):238-241.

[74] Diego Franciotta, Anna Luisa Di Stefano, Sven Jarius, Elisabetta Zardini, Eleonora Tavazzi, Clara Ballerini, Enrico Marchioni, Roberto Bergamaschi, and Mauro Ceroni. Cerebrospinal baff and epsteinbarr virus-specific oligoclonal bands in multiple sclerosis and other inflammatory demyelinating neurological diseases. 230(1-2):160163. 
[75] Paulo Diniz da Gama, Luís Dos Ramos Machado, José Antonio Livramento, Hélio Rodrigues Gomes, Tarso Adoni, Angelina Maria Martins Lino, Paulo Eurípedes Marchiori, Rogério de Rizo Morales, Marco Aurélio Lana-Peixoto, and Dagoberto Callegaro. Study of oligoclonal bands restricted to the cerebrospinal fluid in multiple sclerosis patients in the city of sã\$o paulo. 67(4):10171022.

[76] R. N. Heard, S. M. Teutsch, B. H. Bennetts, S. D. Lee, E. M. Deane, and G. J. Stewart. Lack of restriction of t cell receptor beta variable gene usage in cerebrospinal fluid lymphocytes in acute optic neuritis. 67(5):585-590.

[77] B. Li, H. Dong, J. Zhang, X. Song, and L. Guo. Cerebrospinal fluid IgG profiles and oligoclonal bands in chinese patients with multiple sclerosis. 115(5):319-324.

[78] A. Mygland, T. Trydal, B. U. Vinje, and C. Vedeler. Isoelectric focusing is superior to immunofixation electrophoresis in diagnosing cns inflammation. 115(2):122-125.

[79] F. Piazza, J. C. DiFrancesco, M. L. Fusco, D. Corti, L. Pirovano, B. Frigeni, L. Mattavelli, S. Andreoni, M. Frigo, C. Ferrarese, G. Tredici, and G. Cavaletti. Cerebrospinal fluid levels of baff and april in untreated multiple sclerosis. 220(1-2):104-107.

[80] Stefan Presslauer, Dejan Milosavljevic, Thomas BrÃ14cke, Peter Bayer, Wolfgang HÃ14bl, and Walter HÃ14bl. Elevated levels of 
kappa free light chains in CSF support the diagnosis of multiple sclerosis. 255(10):1508-1514.

[81] Maria José Sá, Lucinda Sequeira, Maria Edite Rio, and Edward J. Thompson. [oligoclonal $\lg G$ bands in the cerebrospinal fluid of portuguese patients with multiple sclerosis: negative results indicate benign disease]. 63(2B):375-379.

[82] F. Sellebjerg and M. Christiansen. Qualitative assessment of intrathecal IgG synthesis by isoelectric focusing and immunodetection: interlaboratory reproducibility and interobserver agreement. 56(2):135-143.

[83] Luisa M. Villar, Jaime Masjuan, María C. Sádaba, Pedro GonzálezPorqué, José Plaza, Alfredo Bootello, and José C. AlvarezCermeño. Early differential diagnosis of multiple sclerosis using a new oligoclonal band test. 62(4):574-577.

[84] M H J. Vogt, C. E. Teunissen, E. lacobaeus, D A M. Heijnen, E C W. Breij, T. Olsson, L. Brundin, J. Killestein, and Christine D. Dijkstra. Cerebrospinal fluid anti-myelin antibodies are related to magnetic resonance measures of disease activity in multiple sclerosis. 80(10):1110-1115.

[85] B. G. Xiao, G. X. Zhang, C. G. Ma, and H. Link. The cerebrospinal fluid from patients with multiple sclerosis promotes neuronal and oligodendrocyte damage by delayed production of nitric oxide in vitro. 142(1-2):114-120. 
[86] S. Y. Yao, C. W. Stratton, W. M. Mitchell, and S. Sriram. Csf oligoclonal bands in ms include antibodies against chlamydophila antigens. 56(9):1168-1176.

[87] H. Link and Y. M. Huang. Oligoclonal bands in multiple sclerosis cerebrospinal fluid: an update on methodology and clinical usefulness. 180:17-28.

[88] P. A. McCombe, N. N. Brown, A. E. Barr, and L. Parkin. Monoclonal immunoglobulin bands in the cerebrospinal fluid. Aust $N Z \mathrm{~J}$ Med, $21: 227-9,1991$.

[89] T. Ben-Hur, O. Abramsky, and Y. River. The clinical significance of a single abnormal immunoglobulin band in cerebrospinal fluid electrophoresis. J Neurol Sci, 136:159-61, 1996.

[90] G Davies, G Keir, EJ Thompson, and G Giovannoni. The clinical significance of an intrathecal monoclonal immunoglobulin band: a follow-up study. Neurology, 60:1163-1106, 2003.

[91] M. Koch, D. Heersema, J. Mostert, A. Teelken, and J. De Keyser. Cerebrospinal fluid oligoclonal bands and progression of disability in multiple sclerosis. 14:797-800.

[92] G. Walsh and R. Jefferis. Post-translational modifications in the context of therapeutic proteins. Nat Biotechnol, 24:1241-52, 2006.

[93] A Petzold, MJ Eikelenboom, D Gveric, G Keir, M Chapman, $\mathrm{RH}$ Lazeron, et al. Markers for different glial cell responses in 
multiple sclerosis: Clinical and pathological correlations. Brain, 125:1462-1473, 2002.

[94] A. Z. Zeman, D. Kidd, B. N. McLean, M. A. Kelly, D. A. Francis, D. H. Miller, B. E. Kendall, P. Rudge, E. J. Thompson, and W. I. McDonald. A study of oligoclonal band negative multiple sclerosis. 60:27-30.

[95] M. P. Amato and G. Ponziani. A prospective study on the prognosis of multiple sclerosis. Neurol Sci, 21(4 Suppl 2):S831-8, 2000.

[96] L. M. Villar, P. Gonzalez-Porque, J. Masjuan, J. C. Alvarez-Cermeno, A. Bootello, and G. Keir. A sensitive and reproducible method for the detection of oligoclonal IgM bands. J Immunol Methods, 258:151-5, 2001.

[97] M Espiã $\pm o, V$ Abraira, $R$ Arroyo, L Bau, C C Ã!'mara, L Campos -

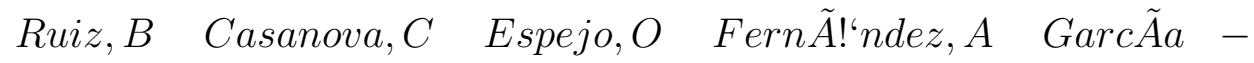

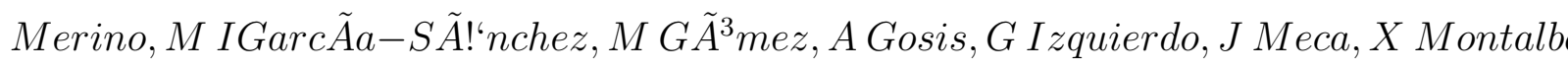
Torrent $\tilde{A}, A$ Rodr $\tilde{A} g u e z-A n t i g \tilde{A} \frac{1}{4} e d a d, G$ Salgado, J LSantiago, E Sarasola, M Sim $\tilde{A}^{3}$ $\begin{array}{lllll}\text { Castell } \tilde{A}^{3}, J & C \text { Alvarez } & - & \text { Cerme } \tilde{A} & \pm\end{array}$ o, andL MVillar.Assessmentof thereproducibilityofoligoclonaligmbanddetection foritsal $67--69$, January 2015.

[98] L. M. Villar, J. Masjuan, P. González-Porqué, J. Plaza, M. C. Sádaba, E. Roldán, A. Bootello, and J. C. Alvarez-Cermeño. Intrathecal igm synthesis in neurologic diseases: relationship with disability in ms. 58(5):824826. 
[99] L. M. Villar, J. Masjuan, P. Gonzalez-Porque, J. Plaza, M. C. Sadaba, E. Roldan, A. Bootello, and J. C. Alvarez-Cermeno. Intrathecal IgM synthesis is a prognostic factor in multiple sclerosis. Ann Neurol, 53:222-6, 2003.

[100] L M Villar, C PicÃ ${ }^{3} n, L$ Costa - Frossard, R Alenda, J Garc $\tilde{A}$ $a$ - Caldentey, $M \quad$ Espi $\tilde{A} \pm o, A \quad$ Muriel, andJ $C \tilde{A}$ lvarezCerme $\tilde{A} \pm$ o.Cerebrospinalfluidimmunologicalbiomarkersassociatedwithaxonaldamageinmultiplescleros $1169--1175$, August2015.

[101] Luisa M Villar, Bonaventura Casanova, Nadia Ouamara, Manuel Comabella, Farzaneh Jalili, David Leppert, Clara de AndrÃ@Cs, Guillermo Izquierdo, Rafael Arroyo, TimuÃßin AvÅar, Sergey V Lapin, Trina Johnson, Xavier MontalbÃ $j n$, Oscar FernÃ $j n d e z$, Roberto Ãlvarez Lafuente, Donna Masterman, MarÃa I GarcÃa-S̃̃ $j n c h e z$, Francisco Coret, Aksel Siva, Evgeniy Evdoshenko, JosÃ@ C Ãlvarez Cerme $\tilde{A} \pm o$, andAmitBar - Or. Immunoglobulinmoligoclonalbands : biomarkeroftargetablein flammationinprimaryprogressivemultiplesclerosis. Annalsofneurolo $231--240$, August2014.

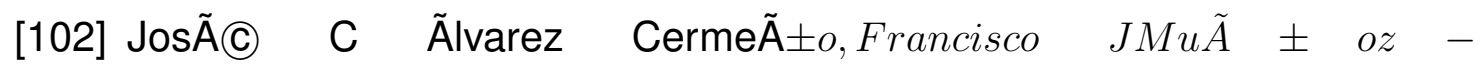
Negrete, LucienneCosta-Frossard, Susana Sainzde laMaza, Luisa MVillar, andGemaReboll specificoligoclonaligmsynthesisassociateswithretinalaxonallossinmultiplesclerosis. Journalo 41 - -44, January 2016.

[103] Diego Franciotta, Marco Salvetti, Francesco Lolli, Barbara Serafini, and Francesca Aloisi. B cells and multiple sclerosis. The Lancet. Neurology, 
7:852-858, September 2008.

[104] P. Morris, N. W. Davies, and G. Keir. A screening assay to detect antigenspecific antibodies within cerebrospinal fluid. 311:81-86.

[105] R. W. Luxton and E. J. Thompson. Affinity distributions of antigen-specific IgG in patients with multiple sclerosis and in patients with viral encephalitis. J Immunol Methods, 131:277-82, 1990.

[106] C. J. Sindic, M. P. Van Antwerpen, and S. Goffette. The intrathecal humoral immune response: laboratory analysis and clinical relevance. Clin Chem Lab Med, 39:333-40, 2001.

[107] K. C. O'Connor, T. Chitnis, D. E. Griffin, S. Piyasirisilp, A. Bar-Or, S. Khoury, K. W. Wucherpfennig, and D. A. Hafler. Myelin basic proteinreactive autoantibodies in the serum and cerebrospinal fluid of multiple sclerosis patients are characterized by low-affinity interactions. J Neuroimmunol, 136:140-8, 2003.

[108] Simone M Brändle, Birgit Obermeier, Makbule Senel, Jessica Bruder, Reinhard Mentele, Mohsen Khademi, Tomas Olsson, Hayrettin Tumani, Wolfgang Kristoferitsch, Friedrich Lottspeich, Hartmut Wekerle, Reinhard Hohlfeld, and Klaus Dornmair. Distinct oligoclonal band antibodies in multiple sclerosis recognize ubiquitous self-proteins. June 2016.

[109] Ryan C Winger and Scott S Zamvil. Antibodies in multiple sclerosis oligoclonal bands target debris. Proceedings of the National Academy of Sciences, page 201609246, 2016. 
[110] BD Trapp, JP Peterson, et al. Axonal transection in the lesions of multiple sclerosis. N Eng J Med, 338:278-285, 1998.

[111] EB Stubbs Jr., MW Lawlor, et al. Anti-neurofilament antibodies in neuropathy with monoclonal gammopathy of undetermined significance produce experimental motor nerve conduction block. Acta Neuropathol, 105:10916, 2003.

[112] Matteo Gastaldi, Elisabetta Zardini, and Diego Franciotta. An update on the use of cerebrospinal fluid analysis as a diagnostic tool in multiple sclerosis. Expert review of molecular diagnostics, 17:31-46, January 2017.

[113] Jorge Correale, MarÃa I GaitÃ Progressive multiple sclerosis: from pathogenic mechanisms to treatment. Brain : a journal of neurology, October 2016.

[114] Manuel Comabella, Jaume Sastre-Garriga, and Xavier Montalban. Precision medicine in multiple sclerosis: biomarkers for diagnosis, prognosis, and treatment response. Current opinion in neurology, 29:254-262, June 2016.

[115] C. MalmestrÃ đm, S. Haghighi, L. Rosengren, O. Andersen, and J. Lycke. Neurofilament light protein and glial fibrillary acidic protein as biological markers in ms. 61(12):1720-1725.

[116] YK Semra, OA Seidi, and MK Sharief. Heightened intrathecal release of axonal cytoskeletal proteins in multiple sclerosis is associated with progressive disease and clinical disability. J Neuroimmunol, 122:132-109, 2002. 
[117] A Petzold, MJ Eikelenboom, G Keir, et al. Axonal damage accumulates in the progressive phase of multiple sclerosis: A 3-year follow-up study. $J$ Neurol Neurosurg Psychiatry, 76:206-211, 2005.

[118] J Brettschneider, A Petzold, A Junker, and H Tumani. Axonal damage markers in cerebrospinal fluid of patients with clinically isolated syndrome improve predicting conversion to definite MS. Multiple Sclerosis, 12:143148, 2006.

[119] A Petzold, K Rejdak, and GT Plant. Axonal degeneration and inflammation in acute optic neuritis. J Neurol Neurosurg Psychiatry, 75:1178-1180, 2004.

[120] C. E. Teunissen, E. lacobaeus, M. Khademi, L. Brundin, N. Norgren, M. J A Koel-Simmelink, M. Schepens, F. Bouwman, H. A M Twaalfhoven, H. J. Blom, C. Jakobs, and C. D. Dijkstra. Combination of CSF n-acetylaspartate and neurofilaments in multiple sclerosis. 72(15):1322-1329.

[121] J. Kuhle, D. Leppert, A. Petzold, A. Regeniter, C. Schindler, M. Mehling, D. C. Anthony, L. Kappos, and R. L P Lindberg. Neurofilament heavy chain in CSF correlates with relapses and disability in multiple sclerosis. 76(14):1206-1213.

[122] J Lycke, O Andersen, and L Rosengren. Neurofilament in cerebrospinal fluid: a potential marker of activity in multiple sclerosis. Eur $J$ Neurol, 3:100, 1996. 
[123] JN Lycke, JE Karlsson, O Andersen, and LE Rosengren. Neurofilament protein in cerebrospinal fluid: a potential marker of activity in multiple sclerosis. J Neurol Neurosurg Psychiatry, 64:402-404, 1998.

[124] Martin Gunnarsson, Clas MalmestrÃ \m, Markus Axelsson, Peter SundstrÃ $₫ \mathrm{~m}$, Charlotte Dahle, Magnus Vrethem, Tomas Olsson, Fredrik Piehl, Niklas Norgren, Lars Rosengren, Anders Svenningsson, and Jan Lycke. Axonal damage in relapsing multiple sclerosis is markedly reduced by natalizumab. 69(1):83-89.

[125] Axel Petzold, Tjeerd Mondria, Jens Kuhle, Maria A Rocca, Jan Cornelissen, Peter Te Boekhorst, Bob Lowenberg, Gavin Giovannoni, Massimo Filippi, Ludwig Kappos, and Rogier Hintzen. Evidence for acute neurotoxicity after chemotherapy. 68(6):806-815.

[126] Axel Petzold. The prognostic value of csf neurofilaments in multiple sclerosis at 15-year follow-up. 88:1388-1390.

[127] Georgina Arrambide, Carmen Espejo, Herena Eixarch, Luisa M Villar, JosÃ@ C AlvarezCerme $\tilde{A} \pm o$, CarmenPic $\tilde{A}^{3} n$, JensKuhle, GiulioDisanto, LudwigKappos, JaumeSastreGarriga, DeborahPareto, EvaSimon, ManuelComabella, JordiRÃo, CarlosNos, CarmenTur, JoaquÃnCastill $\tilde{A}^{3}$, AngelaVidal

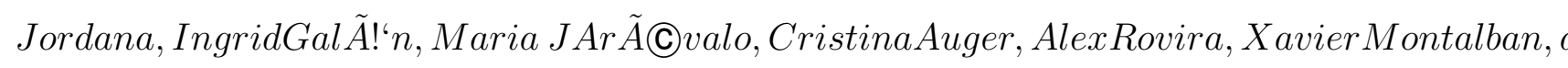
1076 - -1084, September 2016.

[128] Jens Kuhle, Christian Barro, Giulio Disanto, Amandine Mathias, Charlotte Soneson, Guillaume Bonnier, Ãzguer Yaldizli, Axel Regeniter, Tobias Der- 
fuss, Mathieu Canales, Myriam Schluep, Renaud Du Pasquier, Gunnar Krueger, and Cristina Granziera. Serum neurofilament light chain in early relapsing remitting $\mathrm{ms}$ is increased and correlates with csf levels and with mri measures of disease severity. Multiple sclerosis (Houndmills, Basingstoke, England), 22:1550-1559, October 2016.

[129] Axel Petzold, Martijn D Steenwijk, Judith M Eikelenboom, Mike P Wattjes, and Bernard Mj Uitdehaag. Elevated csf neurofilament proteins predict brain atrophy: A 15-year follow-up study. Multiple sclerosis (Houndmills, Basingstoke, England), 22:1154-1162, August 2016.

[130] Kelly Hares, Juliana Redondo, Kevin Kemp, Claire Rice, Neil Scolding, and Alastair Wilkins. Axonal motor protein kif5a and associated cargo deficits in multiple sclerosis lesional and normal-appearing white matter. Neuropathology and applied neurobiology, 2016.

[131] A Petzold, G Keir, AJE Green, G Giovannoni, and EJ Thompson. A specific ELISA for measuring neurofilament heavy chain phosphoforms. J Immunol Methods, 278:179-190, 2003.

[132] LE Rosengren, JE Karlsson, JO Karlsson, LI Persson, and C Wikkelso. Patients with amyotrophic lateral sclerosis and other neurodegenerative diseases have increased levels of neurofilament protein in CSF. J Neurochem, 67:2013-2018, 1996.

[133] N Norgren, L Rosengren, and T Stigbrand. Elevated neurofilament levels in neurological diseases. 987(1):25-31. 
[134] S. Modvig, M. Degn, B. Sander, H. Horwitz, B. Wanscher, F. Sellebjerg, and J. L. Frederiksen. Cerebrospinal fluid neurofilament light chain levels predict visual outcome after optic neuritis. pages 590-598.

[135] Giulio Disanto, Rocco Adiutori, Ruth Dobson, Vittorio Martinelli, Gloria Dalla Costa, Tessel Runia, Evgeniy Evdoshenko, Eric Thouvenot, Maria Trojano, Niklas Norgren, Charlotte Teunissen, Ludwig Kappos, Gavin Giovannoni, Jens Kuhle, and International Clinically Isolated Syndrome Study Group. Serum neurofilament light chain levels are increased in patients with a clinically isolated syndrome. Journal of neurology, neurosurgery, and psychiatry, 87:126-129, February 2016.

[136] G. Disanto, R. Adiutori, R. Dobson, V. Martinelli, G. Dalla Costa, T. Runia, E. Evdoshenko, E. Thouvenot, M. Trojano, N. Norgren, C. Teunissen, L. Kappos, G. Giovannoni, and J. Kuhle. Serum neurofilament light chain levels are increased in patients with a clinically isolated syndrome.

[137] Jens Kuhle, Giulio Disanto, Johannes Lorscheider, Tracy Stites, Yu Chen, Frank Dahlke, Gordon Francis, Anupama Shrinivasan, Ernst-Wilhelm Radue, Gavin Giovannoni, and Ludwig Kappos. Fingolimod and csf neurofilament light chain levels in relapsing-remitting multiple sclerosis. 84(16):1639-1643.

[138] C. Tortorella, V. Direnzo, P. Taurisano, R. Romano, M. Ruggieri, S. Zoccolella, M. Mastrapasqua, T. Popolizio, G. Blasi, A. Bertolino, and M. Trojano. Cerebrospinal fluid neurofilament tracks fmri correlates of attention at the first attack of multiple sclerosis. 21(4):396-401. 
[139] Sandra Amor, Baukje J. van der Star, Isabel Bosca, Joel Raffel, Sharmilee Gnanapavan, Jonathan Watchorn, Jens Kuhle, Gavin Giovannoni, David Baker, Andrea Malaspina, and Fabiola Puentes. Neurofilament light antibodies in serum reflect response to natalizumab treatment in multiple sclerosis.

[140] M. M. Gresle, Y. Liu, L. F. Dagley, J. Haartsen, F. Pearson, A. W. Purcell, L. Laverick, A. Petzold, R. M. Lucas, A. Van der Walt, H. Prime, D. R. Morris, B. V. Taylor, G. Shaw, and H. Butzkueven. Serum phosphorylated neurofilament-heavy chain levels in multiple sclerosis patients. pages 1209-1213.

[141] J. Kuhle, C. MalmestrÃ $₫ m$, M. Axelsson, K. Plattner, O. Yaldizli, T. Derfuss, G. Giovannoni, L. Kappos, and J. Lycke. Neurofilament light and heavy subunits compared as therapeutic biomarkers in multiple sclerosis.

[142] A Petzold, D Baker, G Pryce, et al. Quantification of neurodegeneration by measurement of brain-specific proteins. J Neuroimmunol, 138:45-48, 2003.

[143] Kelly Hares, Kevin Kemp, Elizabeth Gray, Neil Scolding, and Alastair Wilkins. Neurofilament dot blot assays: novel means of assessing axon viability in culture. 198(2):195-203.

[144] G Shaw, C Yang, R Ellis, K Anderson, et al. Hyperphosphorylated neurofilament NF-H is a serum biomarker for axonal injury. 336:1268-1277. 
[145] J Kuhle, A Regeniter, D Leppert, M Mehling, L Kappos, RLP Lindberg, and A Petzold. A highly sensitive electrochemiluminescence immunoassay for the neurofilament heavy chain protein. 220:114-119.

[146] W.F. Abdo, B.P. van de Warrenburg, M. Munneke, W.J. van Geel, B.R. Bloem, H.P. Kremer, and M.M. Verbeek. CSF analysis differentiates multiple-system atrophy from idiopathic late-onset cerebellar ataxia. 67:474-479.

[147] Jens Kuhle, Christian Barro, Ulf Andreasson, Tobias Derfuss, Raija Lindberg, Ãsa Sandelius, Victor Liman, Niklas Norgren, Kaj Blennow, and Henrik Zetterberg. Comparison of three analytical platforms for quantification of the neurofilament light chain in blood samples: Elisa, electrochemiluminescence immunoassay and simoa. Clinical chemistry and laboratory medicine, 54:1655-1661, October 2016.

[148] Marguerite Limberg, Giulio Disanto, Christian Barro, and Jens Kuhle. Neurofilament light chain determination from peripheral blood samples. Methods in molecular biology (Clifton, N.J.), 1304:93-98, 2016.

[149] A. Petzold, D. Gveric, M. Groves, K. Schmierer, D. Grant, M. Chapman, G. Keir, L. Cuzner, and E. J. Thompson. Phosphorylation and compactness of neurofilaments in multiple sclerosis: indicators of axonal pathology. 213:326-335.

[150] A Petzold, MJ Eikelenboom, G Keir, et al. The new Global Multiple Sclerosis Severity Score (MSSS) correlates with axonal but not glial biomarkers. Multiple Sclerosis, 12:325-328, 2006. 
[151] P.A. Cloos and S. Christgau. Post-translational modifications of proteins: implications for aging, antigen recognition, and autoimmunity. 5(3):139158.

[152] F. Delom and E. Chevet. Phosphoprotein analysis: from proteins to proteomes. 4:15.

[153] X. Yao, H.Y. Kwan, and Y. Huang. Regulation of TRP channels by phosphorylation. 14:273-280.

[154] J.J. Ventura and A.R. Nebreda. Protein kinases and phosphatases as therapeutic targets in cancer. Clin Transl Oncol, 8:153-60, 2006.

[155] A.R. Forrest, D.F. Taylor, J.L. Fink, M.M. Gongora, C. Flegg, R.D. Teasdale, H. Suzuki, M. Kanamori, C. Kai, Y. Hayashizaki, and S.M. Grimmond. PhosphoregDB: the tissue and sub-cellular distribution of mammalian protein kinases and phosphatases. 7:82.

[156] J.Q. Wang, A. Arora, L. Yang, N.K. Parelkar, G. Zhang, X. Liu, E.S. Choe, and L. Mao. Phosphorylation of AMPA receptors: mechanisms and synaptic plasticity. 32:237-249.

[157] C.S. Rye and J.B. Baell. Phosphate isosteres in medicinal chemistry. 12:3127-3141.

[158] S.A. Lieser, B.E. Aubol, L. Wong, P.A. Jennings, and J.A. Adams. Coupling phosphoryl transfer and substrate interactions in protein kinases. Biochim Biophys Acta, 1754:191-109, 2005. 
[159] K. Shen, A.C. Hines, D. Schwarzer, K.A. Pickin, and P.A. Cole. Protein kinase structure and function analysis with chemical tools. 1754:65-78.

[160] J.r. Roskoski R. Src kinase regulation by phosphorylation and dephosphorylation. Biochem Biophys Res Commun, 331:1-14, 2005.

[161] B.L. Lua and B.C. Low. Cortactin phosphorylation as a switch for actin cytoskeletal network and cell dynamics control. 579:577-585.

[162] C. Horbinski and C.T. Chu. Kinase signaling cascades in the mitochondrion: a matter of life or death. Free Radic Biol Med, 38:2-11, 2005.

[163] F. Chen, D. David, A. Ferrari, and J. Gotz. Posttranslational modifications of tau-role in human tauopathies and modeling in transgenic animals. 5:503-515.

[164] A. Krupa, G. Preethi, and N. Srinivasan. Structural modes of stabilization of permissive phosphorylation sites in protein kinases: distinct strategies in Ser/Thr and Tyr kinases. 339:1025-1039.

[165] M.J. Carden, W.W. Schlaepfer, and V.M. Lee. The structure, biochemical properties, and immunogenicity of neurofilament peripheral regions are determined by phosphorylation state. 260:9805-9817.

[166] G. Harauz and A.A. Musse. A Tale of Two Citrullines-Structural and Functional Aspects of Myelin Basic Protein Deimination in Health and Disease. Neurochem Res, pages 687-600, 2006.

[167] M. Piacentini and V. Colizzi. Tissue transglutaminase: apoptosis versus autoimmunity. Immunol Today, 20:130-104, 1999. 
[168] G. Virella, S.R. Thorpe, N.L. Alderson, E.M. Stephan, D. Atchley, F. Wagner, and M.F. Lopes-Virella. Autoimmune response to advanced glycosylation end-products of human LDL. 44:487-493.

[169] Jonathan Witherick, Alastair Wilkins, Neil Scolding, and Kevin Kemp. Mechanisms of oxidative damage in multiple sclerosis and a cell therapy approach to treatment. Autoimmune diseases, 2011, 2010.

[170] WW Schlaepfer, C Lee, VMY Lee, and UJP Zimmerman. An immunoblot study of neurofilament degradation in situ and during calcium-activated proteolysis. J Neurochem, 44:502-509, 1985.

[171] S Wang, GJ Lees, LE Rosengren, JE Karlsson, A Hamberger, and KG Haglid. Proteolysis of filament proteins in glial and neuronal cells after in vivo stimulation of hippocampal NMDA receptors. Neurochem Res, 17:1005-1009, 1992.

[172] WJA Van Geel, LE Rosengren, and MM Verbeek. An enzyme immunoassay to quantify neurofilament light chain in cerebrospinal fluid. 296:179185.

[173] ME Goldstein, NH Sternberger, and LA Sternberger. Phosphorylation protects neurofilaments against proteolysis. J Neuroimmunol, 14:149-160, 1987.

[174] HC Pant. Dephosphorylation of neurofilament proteins enhances their susceptibility to degradation by calpain. Biochem J, 256:665-608, 1988. 
[175] D.N. Irani, C. Anderson, R. Gundry, R. Cotter, S. Moore, D.A. Kerr, J.C. McArthur, N. Sacktor, C.A. Pardo, M. Jones, P.A. Calabresi, and A. Nath. Cleavage of cystatin $C$ in the cerebrospinal fluid of patients with multiple sclerosis. 59:237-247.

[176] O. Carrette, P.R. Burkhard, S. Hughes, D.F. Hochstrasser, and J.C. Sanchez. Truncated cystatin C in cerebrospiral fluid: Technical [corrected] artefact or biological process? Proteomics, 5:3060-3005, 2005.

[177] L Steinman. Multiple approaches to multiple sclerosis. Nat Med, 6:15-6, 2000.

[178] L Steinman. Multiple sclerosis: a coordinated immunological attack against myelin in the central nervous system. 85:299-302.

[179] S.S. Zamvil, D.J. Mitchell, A.C. Moore, K. Kitamura, L. Steinman, and J.B. Rothbard. T-cell epitope of the autoantigen myelin basic protein that induces encephalomyelitis. 324:258-260.

[180] M.A. Moscarello, D.D. Wood, C. Ackerley, and C. Boulias. Myelin in multiple sclerosis is developmentally immature. J Clin Invest, 94:146-54, 1994.

[181] L.B. Pritzker, S. Joshi, G. Harauz, and M.A. Moscarello. Deimination of myelin basic protein. 2. Effect of methylation of MBP on its deimination by peptidylarginine deiminase. Biochemistry, 39:5382-5308, 2000.

[182] N. Fujii, Y. Ishibashi, K. Satoh, M. Fujino, and K. Harada. Simultaneous racemization and isomerization at specific aspartic acid residues in alpha 
B-crystallin from the aged human lens. Biochim Biophys Acta, 1204:15763, 1994.

[183] M.J. van Stipdonk, A.A. Willems, S. Amor, C. Persoon-Deen, P.J. Travers, C.J. Boog, and J.M. van Noort. T cells discriminate between differentially phosphorylated forms of alphaB-crystallin, a major central nervous system myelin antigen. Int Immunol, 10:943-950, 1998.

[184] C.E. Voorter, W.A. de Haard-Hoekman, P.J. van den Oetelaar, H. Bloemendal, and W.W. de Jong. Spontaneous peptide bond cleavage in aging alpha-crystallin through a succinimide intermediate. J Biol Chem, 263:19020-19003, 1988.

[185] A. Corthay, J. Backlund, J. Broddefalk, E. Michaelsson, T.J. Goldschmidt, J. Kihlberg, and R. Holmdahl. Epitope glycosylation plays a critical role for T cell recognition of type II collagen in collagen-induced arthritis. 28:25802590.

[186] C. Masson-Bessiere, M. Sebbag, E. Girbal-Neuhauser, L. Nogueira, C. Vincent, T. Senshu, and G. Serre. The major synovial targets of the rheumatoid arthritis-specific antifilaggrin autoantibodies are deiminated forms of the alpha- and. 166:4177-4184.

[187] E. Girbal-Neuhauser, J.J. Durieux, M. Arnaud, P. Dalbon, M. Sebbag, C. Vincent, M. Simon, T. Senshu, C. Masson-Bessiere, C. JolivetReynaud, M. Jolivet, and G. Serre. The epitopes targeted by the rheumatoid arthritis-associated antifilaggrin autoantibodies are posttranslationally 
generated on various sites of (pro)filaggrin by deimination of arginine residues. 162:585-594.

[188] H. Asaga, M. Yamada, and T. Senshu. Selective deimination of vimentin in calcium ionophore-induced apoptosis of mouse peritoneal macrophages. Biochem Biophys Res Commun, 243:641-606, 1998.

[189] M. Inagaki, H. Takahara, Y. Nishi, K. Sugawara, and C. Sato. Ca2+-dependent deimination-induced disassembly of intermediate filaments involves specific modification of the amino-terminal head domain. 264:18119-18127.

[190] M.M. Newkirk, R. Goldbach-Mansky, J. Lee, J. Hoxworth, A. McCoy, C. Yarboro, J. Klippel, and H.S. El-Gabalawy. Advanced glycation endproduct (AGE)-damaged IgG and IgM autoantibodies to IgG-AGE in patients with early synovitis. Arthritis Res Ther, 5:R82-90, 2003.

[191] J. Brange, L. Langkjaer, S. Havelund, and A. Volund. Chemical stability of insulin. 1. Hydrolytic degradation during storage of pharmaceutical preparations. 9:715-726.

[192] S.M. Trigwell, P.M. Radford, S.R. Page, A.C. Loweth, R.F. James, N.G. Morgan, and I. Todd. Islet glutamic acid decarboxylase modified by reactive oxygen species is recognized by antibodies from patients with type 1 diabetes mellitus. Clin Exp Immunol, 126:242-209, 2001.

[193] A.L. Young, W.G. Carter, H.A. Doyle, M.J. Mamula, and D.W. Aswad. Structural integrity of histone $\mathrm{H} 2 \mathrm{~B}$ in vivo requires the activity of protein 
L-isoaspartate O-methyltransferase, a putative protein repair enzyme. $J$ Biol Chem, 276:37161-37105, 2001.

[194] J.H. Kim, K.H. Nam, O.S. Kwon, I.G. Kim, M. Bustin, H.E. Choy, and S.C. Park. Histone cross-linking by transglutaminase. Biochem Biophys Res Commun, 293:1453-1407, 2002.

[195] M.J. Mamula, R.J. Gee, J.I. Elliott, A. Sette, S. Southwood, P.J. Jones, and P.R. Blier. Isoaspartyl post-translational modification triggers autoimmune responses to self-proteins. J Biol Chem, 274:22321-22307, 1999.

[196] F. Monneaux, J.M. Lozano, M.E. Patarroyo, J.P. Briand, and S. Muller. T cell recognition and therapeutic effect of a phosphorylated synthetic peptide of the 70K snRNP protein administered in MR/pr mice. 33:287-296.

[197] L. Cao, D. Sun, and J.N. Whitaker. Citrullinated myelin basic protein induces experimental autoimmune encephalomyelitis in Lewis rats through a diverse T cell repertoire. J Neuroimmunol, 88:21-9, 1998.

[198] J.A. Hill, S. Southwood, A. Sette, A.M. Jevnikar, D.A. Bell, and E. Cairns. Cutting edge: the conversion of arginine to citrulline allows for a. 171:538541.

[199] L.M. Sollid. Molecular basis of celiac disease. 18:53-81.

[200] D.M. Wuttge, M. Bruzelius, and S. Stemme. T-cell recognition of lipid peroxidation products breaks tolerance to self proteins. Immunology, 98:273209, 1999. 
[201] Anthony P. Nicholas, Thiagarajan Sambandam, Joshua D. Echols, and Wallace W. Tourtellotte. Increased citrullinated glial fibrillary acidic protein in secondary progressive multiple sclerosis. 473(1):128-136.

[202] G. Harauz, N. Ishiyama, C.M. Hill, I.R. Bates, D.S. Libich, and C. Fares. Myelin basic protein-diverse conformational states of an intrinsically unstructured protein and its roles in myelin assembly and multiple sclerosis. 35:503-542.

[203] J.M. Boggs. Myelin basic protein: a multifunctional protein. Cell Mol Life Sci, pages 503-500, 2006.

[204] A.A. Musse, J.M. Boggs, and G. Harauz. Deimination of membrane-bound myelin basic protein in multiple sclerosis exposes an immunodominant epitope. Proc Natl Acad Sci U S A, 103:4422-4407, 2006.

[205] Hester A Doyle and Mark J Mamula. Post-translational protein modifications in antigen recognition and autoimmunity. 22(8):443-449.

[206] H.A. Doyle and M.J. Mamula. Posttranslational protein modifications: new flavors in the menu of autoantigens. Curr Opin Rheumatol, 14:244-209, 2002.

[207] H.A. Doyle and M.J. Mamula. Posttranslational modifications of selfantigens. 1050:1-9.

[208] C. Husted. Structural insight into the role of myelin basic protein in multiple sclerosis. 103:4339-4340. 
[209] D.D. Wood, J.M. Bilbao, P. O'Connors, and M.A. Moscarello. Acute multiple sclerosis (Marburg type) is associated with developmentally immature myelin basic protein. 40:18-24.

[210] J.W. Lamensa and M.A. Moscarello. Deimination of human myelin basic protein by a peptidylarginine deiminase from bovine brain. 61:987-996.

[211] L.B. Pritzker, T.A. Nguyen, and M.A. Moscarello. The developmental expression and activity of peptidylarginine deiminase in the mouse. Neurosci Lett, 266:161-104, 1999.

[212] M.A. Moscarello, L. Pritzker, F.G. Mastronardi, and D.D. Wood. Peptidylarginine deiminase: a candidate factor in demyelinating disease. 81:335343.

[213] F.G. Mastronardi and M.A. Moscarello. Molecules affecting myelin stability: a novel hypothesis regarding the pathogenesis of multiple sclerosis. 80:301-308.

[214] J. De Keyser, M. Schaaf, and A. Teelken. Peptidylarginine deiminase activity in postmortem white matter of patients with multiple sclerosis. Neurosci Lett, 260:74-6, 1999.

[215] J. de Seze, S. Dubucquoi, D. Lefranc, F. Virecoulon, I. Nuez, V. Dutoit, P. Vermersch, and L. Prin. IgG reactivity against citrullinated myelin basic protein in multiple sclerosis. J Neuroimmunol, 117:149-55, 2001.

[216] R. Raijmakers, J. Vogelzangs, J. Raats, M. Panzenbeck, M. Corby, H. Jiang, M. Thibodeau, N. Haynes, W.J. Van Venrooij, G.J. Pruijn, and 
B. Werneburg. Experimental autoimmune encephalomyelitis induction in peptidylarginine deiminase 2 knockout mice. 498:217-226.

[217] O.A. Bizzozero, G. DeJesus, K. Callahan, and A. Pastuszyn. Elevated protein carbonylation in the brain white matter and gray matter of patients with multiple sclerosis. 81:687-695.

[218] J. M. Anderson, D. W. Hampton, R. Patani, G. Pryce, R. A. Crowther, R. Reynolds, R. J M Franklin, G. Giovannoni, D. A S Compston, D. Baker, M. G. Spillantini, and S. Chandran. Abnormally phosphorylated tau is associated with neuronal and axonal loss in experimental autoimmune encephalomyelitis and multiple sclerosis. 131(Pt 7):1736-1748.

[219] A Schneider, G Wright Araujo, K Trajkovic, et al. Hyperphosphorylation and aggregation of tau in experimental autoimmune encephalomyelitis. pages 55833-55839.

[220] H. Bartosik-Psujek and Z. Stelmasiak. The CSF levels of total-tau and phosphotau in patients with relapsing-remitting multiple sclerosis. J Neural Transm, pages (epub ahead of print - 6.July 2005), 2005.

[221] J. Brettschneider, M. Maier, S. Arda, A. Claus, S.D. Sussmuth, J. Kassubek, and $\mathrm{H}$. Tumani. Tau protein level in cerebrospinal fluid is increased in patients with early multiple sclerosis. 11(3):261-265.

[222] H. Bartosik-Psujek and JJ Archelos. Tau protein and 14-3-3 are elevated in the cerebrospinal fluid of patients with multiple sclerosis and correlate with intrathecal synthesis of IgG. J Neurol, 251:414-20, 2004. 
[223] E. Kapaki, G.P. Paraskevas, M. Michalopoulou, and K. Kilidireas. Increased cerebrospinal fluid tau protein in multiple sclerosis. 43:228-232.

[224] I. Guimaraes, M.I. Cardoso, and M.J. Sa. Tau protein seems not to be a useful routine clinical marker of axonal damage in multiple sclerosis. Mult Scler, 12:354-306, 2006.

[225] F.J. Jimenez-Jimenez, J.M. Zurdo, A. Hernanz, S. Medina-Acebron, F. de Bustos, B. Barcenilla, Y. Sayed, and L. Ayuso-Peralta. Tau protein concentrations in cerebrospinal fluid of patients with multiple sclerosis. Acta Neurol Scand, 106:351-304, 2002.

[226] E. T. Lim, D. Grant, M. Pashenkov, G. Keir, E. J. Thompson, M. SÃ $\llbracket$ derstrÃ $₫ m$, and G. Giovannoni. Cerebrospinal fluid levels of brain specific proteins in optic neuritis. 10(3):261-265.

[227] RHSR Roxburgh, SR Seaman, T Masterman, AE Hensiek, SJ Sawcer, $S$ Vukusic, et al. Multiple Sclerosis Severity Score. Using disability and disease duration to rate disease severity. 64:1144-1151.

[228] A.M. Nilselid, P. Davidsson, K. Nagga, N. Andreasen, P. Fredman, and K. Blennow. Clusterin in cerebrospinal fluid: analysis of carbohydrates and quantification of native and glycosylated forms. 48:718-728. 